\title{
cjrABC-sen $B$ hinders survival of extraintestinal pathogenic $E$. coli in the bloodstream through triggering complement-mediated killing
}

Wen-Chun Huang ${ }^{1,2+}$, Yi-Jyun Liao ${ }^{1+}$, Masayuki Hashimoto ${ }^{1,2,3}$, Kuan-Fu Chen ${ }^{1}$, Chishih Chu ${ }^{4}$, Po-Chuen Hsu', Shuying Wang ${ }^{2,3,5,6}$ and Ching-Hao Teng ${ }^{1,2,3^{*}}$ (D)

\begin{abstract}
Background: Extraintestinal pathogenic E. coli (ExPEC) is a common gram-negative organism causing various infections, including urinary tract infections (UTIs), bacteremia, and neonatal meningitis. The cjrABC-senB gene cluster of E. coli contributes to ExPEC virulence in the mouse model of UTIs. Consistently, the distribution of cjrABC$\operatorname{sen} B$ is epidemiologically associated with human UTIs caused by E. coli. cjrABC-senB, which has previously been proposed to encode an iron uptake system, may facilitate ExPEC survival in the iron availability-restricted urinary tract. Given that the bloodstream is also an iron limited environment to invading bacteria, the pathogenic role of cjrABC-senB in ExPEC bacteremia, however, remains to be investigated.
\end{abstract}

Methods: The ability of ExPEC RS218 strains with and without cjrABC-senB to survive in the mouse bloodstream and human serum was evaluated. Subsequently, the role of this gene cluster in the ExPEC interaction with the complement system was evaluated. Finally, the distribution of $c j r A B C-\operatorname{sen} B$ in human clinical E. coli isolates was determined by PCR. The frequency of cjrABC-senB in bacteremia isolates that were not associated with UTIs (nonUTI bacteremia isolates) was compared with that in UTI-associated isolates and fecal isolates.

Results: Expression of cjrABC-senB attenuated the survival of RS218 in the mouse bloodstream and human serum. The cjrABC-senB-harboring strains triggered enhanced classical- and alternative-complement pathway activation and became more vulnerable to complement-mediated killing in serum. cjrA was identified as the major gene responsible for the attenuated serum survival. Expressing cjrABC-senB and $\operatorname{cj} A$ increased bacterial susceptibility to detergent and induced periplasmic protein leakage, suggesting that the expression of these genes compromises the integrity of the outer membrane of ExPEC. In addition, the frequency of cjrABC-senB in non-UTI bacteremia isolates was significantly lower than that in UTI-associated isolates, while the frequencies in non-UTI bacteremia (Continued on next page)

\footnotetext{
* Correspondence: chteng@mail.ncku.edu.tw

'Wen-Chun Huang and Yi-Jyun Liao are contributed equally to this work 'Institute of Molecular Medicine, College of Medicine, National Cheng Kung University, 4th F, 367 Sheng Li Road, North District, Tainan City, Taiwan ${ }^{2}$ Institute of Basic Medical Sciences, College of Medicine, National Cheng Kung University, Tainan City, Taiwan

Full list of author information is available at the end of the article
}

C C The Author(s). 2020 Open Access This article is licensed under a Creative Commons Attribution 4.0 International License, which permits use, sharing, adaptation, distribution and reproduction in any medium or format, as long as you give appropriate credit to the original author(s) and the source, provide a link to the Creative Commons licence, and indicate if changes were made. The images or other third party material in this article are included in the article's Creative Commons licence, unless indicated otherwise in a credit line to the material. If material is not included in the article's Creative Commons licence and your intended use is not permitted by statutory regulation or exceeds the permitted use, you will need to obtain permission directly from the copyright holder. To view a copy of this licence, visit http://creativecommons.org/licenses/by/4.0/ The Creative Commons Public Domain Dedication waiver (http://creativecommons.org/publicdomain/zero/1.0/) applies to the data made available in this article, unless otherwise stated in a credit line to the data. 


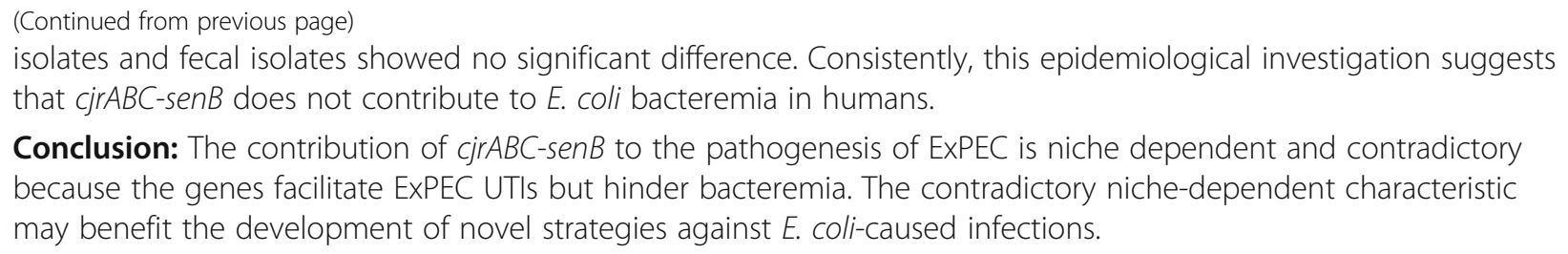

Keywords: Extraintestinal pathogenic E. coli, cjrA, cjrB, cjrC, senB, cjrABC-senB, ExPEC, Urinary tract infections, Bacteremia

\section{Background}

Extraintestinal pathogenic E. coli (ExPEC) is one of the major causes of extraintestinal infections, such as urinary tract infections (UTIs), bacteremia, and neonatal meningitis [1]. Antibiotic treatment is the traditional measure used to treat E. coli-caused infections. However, the rapid emergence of antibiotic-resistant strains has become a critical issue for managing these infections [1-3]. The development of novel antimicrobial strategies is desperately needed. Given that bacterial virulence factors are potential targets for developing such strategies, understanding the roles of the virulence factors and the ways they facilitate infections are fundamental.

The E. coli $\operatorname{cj} A B C-\operatorname{sen} B$ gene cluster, which contains the genes $\operatorname{cjr} A, \operatorname{cjr} B, \operatorname{cjr} C$, and $\operatorname{sen} B$, is located on virulence plasmids of many ExPEC strains and has been shown to contribute to the uropathogenesis of ExPEC [4-6]. It is proposed that the gene cluster facilitates iron uptake by ExPEC in the urinary tract, where the availability of iron is low $[4,7,8]$, because the $\operatorname{cj} r A B C$ genes are predicted to encode iron uptake factors. CjrA is homologous to a Pseudomonas aeruginosa protein, PhuW, which is important for heme uptake. CjrB is homologous to TonB proteins of various bacteria, while $\mathrm{CjrC}$ is homologous to TonB-dependent outer membrane heme/hemoglobin or siderophore receptors [5, 9]. It has been noted that many ExPEC virulence factors contribute to infections in different tissues, while some contribute to infection in only specific tissues [1]. As bacterial survival in the bloodstream is a critical step for ExPEC to cause lethal systemic infections, it is of interest to elucidate the role of $\operatorname{cj} A B C-\operatorname{sen} B$ in ExPEC survival in the bloodstream, where iron availability is restricted for invading pathogens $[10,11]$.

The complement system is the first line of innate defense in the bloodstream against invading pathogens. The complement system can be activated by three distinct pathways: the classical, alternative, and lectin pathways [12]. Activation of the three pathways leads to the production and deposition of the complement protein C3b on the surface of invading pathogens. C3b deposition triggers the activation of the downstream common terminal complement pathway, resulting in the formation of membrane attack complexes (MACs) on the pathogen surface, thus killing the pathogen. The direct binding or indirect, antibody-dependent binding of $\mathrm{C} 1 \mathrm{q}$ to invading pathogens can trigger the classical pathway $(\mathrm{CP})$. The alternative pathway (AP) starts with the spontaneous hydrolysis of $\mathrm{C} 3$ to produce $\mathrm{C} 3 \mathrm{~b}$, while the lectin pathway (LP) is initiated by the binding of mannose-binding lectin to the carbohydrate structures on the pathogen surface.

In this study, we found that ExPEC expressing the $\operatorname{cj} A B C-\operatorname{sen} B$ operon induced a significantly lower level of bacteremia in a mouse bacteremia model than cognate strains without this operon. Our results suggest that the complement system in the bloodstream is responsible for the decreased survival of $\operatorname{cj} r A B C$-sen $B$-harboring pathogens. The detailed mechanism was further elucidated within this study.

\section{Methods}

\section{Bacterial strains and plasmids}

E. coli $\mathrm{K} 1$ strain RS218 (O18:K1:H7) is a bacteremia clinical isolates which is isolated from the cerebrospinal fluid (CSF) from a neonate with meningitis [13-16]. The spontaneous streptomycin-resistant derivative of RS218 and its derivatives were used in this study (Table 1). The RS218 mutants were constructed by a PCR-based method described previously $[20,21]$ (Table 1). The low-copy-number plasmid pCL1920 was utilized to clone $\operatorname{cj} A B C-\operatorname{sen} B$ and the individual genes in this gene cluster (Table 1).

The bacteremia E. coli isolates that were not associated with UTIs and biliary tract infections (BTIs) were collected in National Cheng Kung University Hospital between October and December of 2005.

\section{Human sera, and C1q}

The normal human serum (NHS) used in this study was pooled from the serum of 8 healthy adults and stored in aliquots at $-80^{\circ} \mathrm{C}$. Heat-inactivated NHS (HI-NHS) was prepared by heating the NHS at $56^{\circ} \mathrm{C}$ for $30 \mathrm{~min}$. The C1q-depleted and factor B-depleted sera (Calbiochem) supplemented with $5 \mathrm{mM} \mathrm{CaCl} 2$ and $2 \mathrm{mM} \mathrm{MgCl}$ and then diluted with PBS were served and $\mathrm{CP}$ - and AP- 
Table 1 E. coli strains and plasmids used in this study

\begin{tabular}{|c|c|c|}
\hline Strains or plasmids & Relevant information & Sources \\
\hline \multicolumn{3}{|l|}{ E. coli Strains } \\
\hline RS218 (WT-RS218) & $\begin{array}{l}\text { E. coli K1 RS218 isolated from the cerebrospinal fluid } \\
\text { of a neonate with meningitis. }\end{array}$ & {$[16,17]$} \\
\hline NacZ-RS218 & RS218 with a lacZ deletion (The otherwise WT-RS218) & {$[18]$} \\
\hline$\Delta c j r-R S 218$ & RS218 with a $c j r A B C-\operatorname{sen} B$ deletion & This study \\
\hline$\triangle c j r \Delta a C Z-R S 218$ & $\Delta c j r-$ RS218 with a lacZ deletion & This study \\
\hline $\mathrm{Cjr}^{+}-\mathrm{RS} 218$ & $\Delta c j r-R S 218$ harboring pCL1920-cjrABC-senB & This study \\
\hline $\mathrm{Cjr}^{+}-\mathrm{NaCZ}-\mathrm{RS} 218$ & $\mathrm{Cjr}^{+}-\mathrm{RS} 218$ with a lacZ deletion & This study \\
\hline $\mathrm{Cjr}^{-}-\mathrm{RS} 218$ & Acjr-RS218 harboring pCL1920 & This study \\
\hline CjrA-RS218 & Acjr-RS218 harboring pCL1920-cjrA & This study \\
\hline CjrB-RS218 & $\triangle c j r-R S 218$ harboring pCL1920-cjrB & This study \\
\hline CjrC-RS218 & Acjr-RS218 harboring pCL1920-cjrC & This study \\
\hline SenB-RS218 & $\triangle c j r-R S 218$ harboring pCL1920-senB & This study \\
\hline \multicolumn{3}{|l|}{ Plasmids } \\
\hline pCL1920 & Low-copy-number plasmid & {$[19]$} \\
\hline pCL1920-cjrABC-sen $B$ & $\begin{array}{l}\text { pCL1920 harboring cjrABC-senB, which is under the } \\
\text { control of the lac promoter on the plasmid }\end{array}$ & This study \\
\hline pCL1920-cjrA & 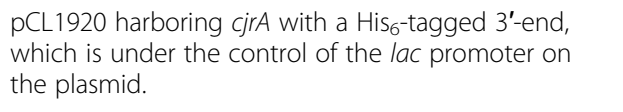 & This study \\
\hline pCL1920-cjrB & $\begin{array}{l}\text { PCL1920 harboring cjrB with a His } \sigma_{\sigma} \text {-tagged } 3^{\prime} \text {-end, } \\
\text { which is under the control of the lac promoter on } \\
\text { the plasmid. }\end{array}$ & This study \\
\hline pCL1920-cjrC & $\begin{array}{l}\text { PCL1920 harboring cjrC with a His--tagged } 3 \text { '-end, } \\
\text { which is under the control of the lac promoter on } \\
\text { the plasmid. }\end{array}$ & This study \\
\hline pCL1920-senB & $\begin{array}{l}\text { PCL1920 harboring senB with a His } s_{6} \text {-tagged } 3 \text { '-end, } \\
\text { which is under the control of the lac promoter on } \\
\text { the plasmid. }\end{array}$ & This study \\
\hline
\end{tabular}

blocked sera. In addition, heat-inactivated $\mathrm{C} 1 \mathrm{q}$ antiserum or heat-inactivated properdin anti-serum (Calbiochem, Darmstadt, Germany, and Sigma-Aldrich, St. Louis, MO) were added to the final concentrations of 10 and 15\% in 40\% NHS diluted with PBS to block CP and AP respectively $[22,23]$. To inhibit the LP pathway, NHS was treated with $100 \mathrm{mM}$ mannose [24]. The purified $\mathrm{C} 1 \mathrm{q}$ protein was purchased from Complement Technology, Inc. (Tyler, TX).

\section{In vivo complement depletion with cobra venom factor (CVF)}

Complement depletion in mice with cobra venom factor CVF) was performed as describe previously [25]. Briefly, CVF (Quidel) was diluted in PBS at a concentration of $2.5 \mathrm{U} / 100 \mu \mathrm{l}$. Mice $(n=15)$ were intraperitoneally injected with $5 \mathrm{U}$ of CVF twice with an interval of $6 \mathrm{~h}$. In the control group, animals $(n=15)$ were injected with $200 \mu \mathrm{l}$ of PBS instead of CVF. At $48 \mathrm{~h}$ after the last CVF/ PBS injection, the animals were subjected to co-infection experiments. Before the infection experiments, the levels of the CVF treatment-induced complement depletion was determined by the $50 \%$ haemolytic complement $\left(\mathrm{CH}_{50}\right)$ activity of serum as previously described [26, 27]. Briefly, $200 \mu$ l mouse serum was serially diluted 2-fold with Veronal Buffered Saline (VBS) and then was incubated with $200 \mu \mathrm{l}$ rabbit red blood cells (RBC) in VBS at $37^{\circ} \mathrm{C}$ for $30 \mathrm{~min}$. The intact $\mathrm{RBC}$ were pelleted by centrifugation at $1500 \mathrm{~g}$ for $5 \mathrm{~min}$ and O.D. 540 of the supernatant was measured. The percentage of hemolysis was used the following formula: hemolysis $(\%)=[(\mathrm{A}-\mathrm{B}) /(\mathrm{C}$ $\mathrm{B})] \times 100 \%$. A is the O.D.540 reading of the RBC incubated with CVF- or PBS-treated serum, B is the O.D. ${ }_{540}$ reading of the RBC incubated with VBS buffer only, and $\mathrm{C}$ is the O.D. ${ }_{540} \mathrm{~nm}$ reading of the $\mathrm{RBC}$ incubated with $\mathrm{H}_{2} \mathrm{O} . \mathrm{H}_{2} \mathrm{O}$ induced the lysis of all the RBC. The lysis percentage induced by the CVF-treated and PBS-treated sera were plotted against dilution factors. Based on the resulting graphs, the dilutions required for 50\% hemolysis $\left(\mathrm{CH}_{50}\right)$ of CVF- and PBS- treated serum were calculated. The $\mathrm{CH}_{50}$ of the CVF-treated serum was approximately $15 \%$ of $\mathrm{CH} 50$ of the PBS-treated serum, 
indicating that CVF treatment induced $85 \%$ of complement depletion in the animals, compared to the PBS treated ones.

\section{The mouse model of $E$. coli bacteremia}

To determine the role of $\operatorname{cj} A B C-\operatorname{sen} B$ in ExPEC bacteremia, equal numbers $\left(1 \times 10^{7} \mathrm{CFU}\right)$ of the E. coli strains with or without these genes were co-inoculated or independently inoculated into 8-week-old BALB/C mice $(n=15)$ thorough intraperitoneal injection as previously described [18]. At $14 \mathrm{~h}$ post-infection, the bacterial blood counts were determined. In the co-inoculation experiments $(n=10)$, the two bacterial strains were differentiated by the colors of their colonies (blue and white) after cultivation on LB agar containing $0.5 \mathrm{mM}$ IPTG and $20 \mu \mathrm{g} / \mathrm{ml} \mathrm{X-gal.}$

\section{Preparation of IgG-depleted serum}

To remove serum IgG, $1 \mathrm{ml}$ of $40 \%$ NHS diluted with phosphate-buffered saline (PBS) was incubated with 0.6 $\mathrm{ml}$ of recombinant protein G-Sepharose (Invitrogen, Grand Island, NY) at $4{ }^{\circ} \mathrm{C}$ for $1 \mathrm{~h}$. The IgG depleted serum was obtained from the supernatant by centrifugation at $1500 \mathrm{~g}$ for $10 \mathrm{~min}$ at $4{ }^{\circ} \mathrm{C}$. More than $90 \%$ of the IgG was removed in the depleted serum based on Western blot analysis (data not shown).

\section{Serum survival assay}

For the serum survival assays with WT-RS218 and $\Delta c j r-$ RS218 (Table 1), $20 \mu \mathrm{l}$ of the overnight bacterial culture was inoculated in $2 \mathrm{ml}$ of fresh LB medium containing $200 \mu \mathrm{M} \mathrm{2}, 2$ '-dipyridyl (DIP), a high affinity of iron chelator, at a ratio of 1:100 for $2 \mathrm{~h}$ to induce the expression of $\operatorname{cj} r A B C-\operatorname{sen} B$ [28]. For the assays performed with the $E$. coli strains transformed with the empty vector pCL1920 or the plasmids harboring the $\operatorname{cjr} A B C-\operatorname{sen} B$ genes (Table 1), overnight cultures of the bacteria were used. These strains didn't need DIP treatment because the $\operatorname{cj} A B C-\operatorname{sen} B$ genes in the plasmids were under the control of the lac promoter provided by the plasmid. The leakage of the lac promoter allowed the constitutive expression of these genes. For the serum survival experiment, E. coli $\left(1 \times 10^{6} \mathrm{CFU}\right)$ cells were incubated at $37^{\circ} \mathrm{C}$ in $100 \mu \mathrm{l}$ of $40 \%$ serum (NHS, HI-NHS, or modified serum) diluted with PBS. After different time periods of incubation, the live bacteria counts were determined by plating the solution on LB agar.

\section{Flow cytometry analysis}

Bacteria $\left(3 \times 10^{6} \mathrm{CFU} / \mathrm{ml}\right)$ were incubated at $37^{\circ} \mathrm{C}$ in $40 \%$ human sera (NHS, HI-NHS, or modified sera with and without heat inactivation) diluted with veronal buffer (Lonza, Walkersville, MD) or in $100 \mu \mathrm{l}$ of veronal buffer containing $25 \mu \mathrm{g} / \mathrm{ml}$ of C1q protein for different time periods. The levels of the serum components deposited on bacteria were determined by probing with the corresponding primary and secondary antibodies as previously described $[18,23]$ and then analyzed on a FACS Calibur $^{\text {Tm }}$ flow cytometer (Becton-Dickinson).

\section{Purification of bacterial outer and inner membrane fractions and lipopolysaccharides}

The bacterial inner and outer membrane fractions were separated using the detergent sodium lauryl sarcosinate as previously described [29]. The lipopolysaccharides (LPS) on the E. coli strains were purified according to methods described by Kariyawasam et al. [30].

\section{Ribonuclease (RNase) leakage assay}

The overnight bacterial culture was adjusted to $\mathrm{OD}_{600}=$ 0.2 in PBS. Then, $10 \mu \mathrm{l}$ of the culture was added to LB agar plates containing $2.5 \%(\mathrm{w} / \mathrm{w})$ Toluidine blue $\mathrm{O}$ and $0.2 \%(\mathrm{w} / \mathrm{w})$ yeast RNA. After incubation for 2 days at $37^{\circ} \mathrm{C}$, pink halos around the bacterial colony on the agar were observed because of the RNase leakage from the periplasm of bacteria [31-33].

\section{Distribution rate of $c j r A B C$-senB in the bacteremia E. coli isolates that were not associated with UTIs and BTIs}

The frequency of $c j r A B C-\operatorname{sen} B$ in the in the bacteremia $E$. coli isolates that were not associated with UTIs and BTIs was determined by PCR as described previously [5].

\section{Statistical analysis}

For the mouse model of $E$. coli bacteremia, the coinfection results were analyzed using a nonparametric Wilcoxon matched-pair test, while the independent infection results were analyzed used non-parametric Mann-Whitney test [34]. Comparisons involving the distribution rates of $\operatorname{cj} A B C-\operatorname{sen} B$ in different groups were measured by using two-tailed Fisher's exact test. For the rest of the experiments, Student's t-test was used. A $P$ value of $<0.05$ was set as the threshold for statistical significance.

\section{Results}

Deletion of $c j r A B C$-sen $B$ increases ExPEC's ability to cause bacteremia

To investigate whether $\operatorname{cjr} A B C-\operatorname{sen} B$ plays a role in ExPEC bacteremia, we utilized the archetypal K1 bacteremia E. coli strain RS218 [14], which harbors a copy of $\operatorname{cj} r A B C-\operatorname{sen} B$ encoded in the plasmid pRS218 [6]. Equal numbers of the wild-type RS218 (WT-RS218) and a cjrABC-senB deletion mutant of RS218 ( $\Delta$ cjr-RS218) were independently inoculated into mice through intraperitoneal injection. At $14 \mathrm{~h}$ post-inoculation the blood counts of the bacteria were determined. As shown in 
Fig. 1a, the bacterial blood counts of $\Delta c j r-R S 218$ were significantly higher than those of WT-RS218, suggesting that expression of $\operatorname{cj} r A B C-\operatorname{sen} B$ decreases RS218 survival in the bloodstream.

In addition, we further investigated whether RS218 strains with and with $\operatorname{cjr} A B C-\operatorname{sen} B$ also show different bloodstream survival when co-inoculated in mice. Equal amounts of $\Delta c j r$-RS218 and the otherwise wild-type RS218 (AlacZ-RS218) were intraperitoneally coinoculated into mice, and the counts of the two strains in the bloodstream was determined at $14 \mathrm{~h}$ postinoculation (lac $Z$ deletion did not affect bloodstream survival of $E$. coli; data not shown). To differentiate and enumerate the bacteria in the bloodstream, blood samples from the infected animals were spread on LB agar containing IPTG and X-gal. The two strains can be differentiated by their colony colors because the colonies of $E$. coli harboring an intact lacZ ( $\Delta c j r$-RS218) would be blue and those of the bacteria without lacZ ( $\triangle$ lacZRS218) would be white on the agar. Consistent with the results of the independent inoculation, $\Delta c j r$-RS218 outcompeted $\Delta$ lacZ-RS218 in the blood (Fig. 1b). Then, we performed a complementary experiment. Equal numbers of the $\Delta c j r$-RS218 strain harboring the low-copy-number plasmid vector pCL1920 and the $\Delta c j r$-RS218 strain with a lacZ deletion ( $\triangle$ cjr $\Delta l a c Z-R S 218$; Table 1$)$ harboring the plasmid encoding $\operatorname{cj} r A B C-\operatorname{sen} B$ (pCL1920-cjrABC- $\operatorname{sen} B$; Table 1) were inoculated intraperitoneally into animals, and the blood counts of each bacteria were determined at $14 \mathrm{~h}$ post-inoculation by plating on LB agar containing IPTG and X-gal. Consistently, the strain without $\operatorname{cjr} A B C-\operatorname{sen} B$ outcompeted the strain with this gene cluster (Fig. 1c). These results further confirmed that the expression of $\operatorname{cj} A B C-\operatorname{sen} B$ hinders bacterial survival in the bloodstream.

Because serum-mediated killing is one of the major defenses against invading bacterial pathogens in the bloodstream, we investigated whether $\operatorname{cj} A B C-\operatorname{sen} B$ is involved in the serum survival of RS218. RS218 strains with and without $\operatorname{cjr} A B C-\operatorname{sen} B$ were independently cultured in $40 \%$ normal human serum (NHS) or $40 \%$ heat-inactivated NHS (HI-NHS). After $1 \mathrm{~h}$ and 3 $\mathrm{h}$ incubation, the counts of live bacteria were determined. WT-RS218 showed significantly lower survival than $\Delta c j r$-RS218 after $3 \mathrm{~h}$ of incubation in NHS (Fig. 1d). A complementary experiment showed consistent results. The $\Delta c j r-\mathrm{RS} 218$ strain trans-complemented with pCL1920-cjrABC-senB (this strain was designated $\mathrm{Cjr}^{+}$-RS218) showed significantly lower survival than the $\Delta c j r$-RS218 strain harboring the plasmid vector pCL1920 (this strain was designated $\mathrm{Cjr}^{-}$-RS218) after $1 \mathrm{~h}$ and $3 \mathrm{~h}$ incubation in NHS (Fig. 1d). These results suggest that expressing $C j r A B C-\operatorname{sen} B$ attenuates ExPEC survival in NHS.

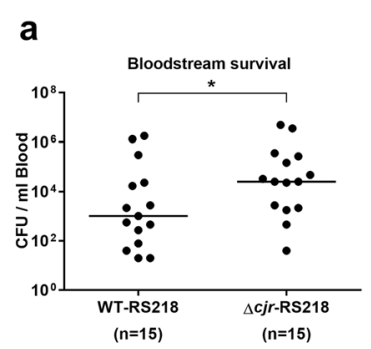

e

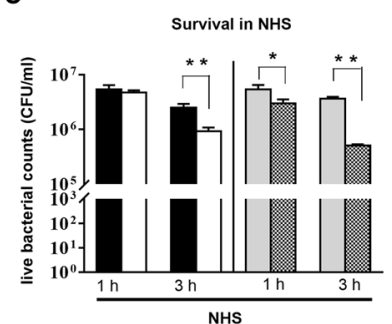

b

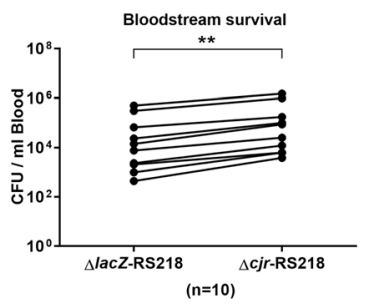

C

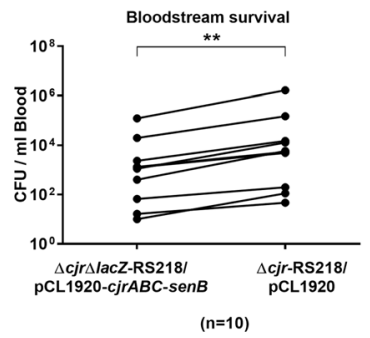

f
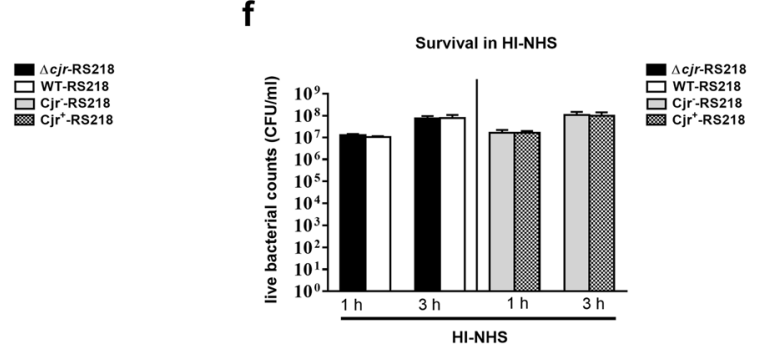

Fig. 1 The survival of RS218 strains with and without cjrABC-senB in the mouse bloodstream and human serum. (a) Independent infections of mice with WT-RS218 and $\triangle c j r$-RS218 $\left(1 \times 10^{7} \mathrm{CFU} /\right.$ mouse). Bacterial blood counts were determined at $14 \mathrm{~h}$ post-inoculation. (b) Coinfection of mice with equal numbers of $\triangle c j$ r-RS218 and $\triangle a C Z$-RS218 $\left(1 \times 10^{7} \mathrm{CFU} / \mathrm{strain} /\right.$ mouse). Bacterial blood counts were determined at $14 \mathrm{~h}$ post-

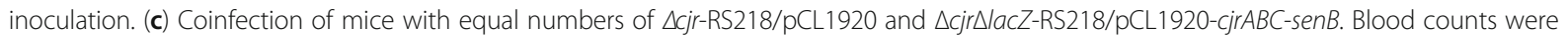
determined at $14 \mathrm{~h}$ post-infection. The horizontal bars represent the median values. For (b) and (c) the bacterial counts derived from same animals are connected with lines. (d) and (e) The serum survival of the RS218 strains with and without cjrABC-senB $\left(1 \times 10^{7} \mathrm{CFU} / \mathrm{ml}\right)$ after $1 \mathrm{~h}$ and $3 \mathrm{~h}$ incubation in $40 \% \mathrm{NHS}$ (d) and $40 \% \mathrm{HI}-\mathrm{NHS}(\mathbf{e})$. The results are shown as the means \pm standard deviations, and the data are representative of three independent experiments performed in triplicate. ${ }^{*}, P$ value $<0.05 ;{ }^{* *}, P$ value $<0.01 ;{ }^{* *}, P$ value $<0.001$ 
However, in HI-NHS, the $\operatorname{cjr} A B C$-senB-harboring strains showed survival levels similar to those of the corresponding strains without this gene cluster (Fig. 1e). Given that the complement system plays an important role in resisting invading bacteria in the serum and that the function of this system is heat labile, the results suggest that the complement system may be responsible for the differential killing of the ExPEC strains with and without the $C j r A B C-\operatorname{sen} B$ gene cluster.

\section{cjrABC-sen $B$-expressing ExPEC encounters a stronger complement attack in NHS than cjrABC-senB-deficient ExPEC}

In serum, the levels of $\mathrm{C} 3 \mathrm{~b}$ and MAC deposition on bacteria reflect the intensity of complement activation that occurs on the bacterial surface [18]. To investigate whether ExPEC with and without $\operatorname{cjr} A B C$-senB encounter different levels of complement-mediated attack in the serum, the levels of $\mathrm{C} 3 \mathrm{~b}$ and MAC deposition on $\mathrm{Cjr}^{+}-\mathrm{RS} 218$ and $\mathrm{Cjr}^{-}-\mathrm{RS} 218$ were measured by flow cytometry after incubation with NHS. As shown in Fig. 2a$2 \mathrm{~d}$, after incubation in $40 \% \mathrm{NHS}$ for 2 and $3 \mathrm{~h}$, the levels of C3b and MAC deposition on $\mathrm{Cjr}^{+}$-RS218 were significantly higher than those on $\mathrm{Cjr}^{-}-\mathrm{RS} 218$, indicating that the presence of $\operatorname{cj} A B C-\operatorname{sen} B$ triggers a stronger complement-mediated attack on the bacteria, which may be responsible for the attenuated ExPEC serum survival due to the expression of this gene cluster.

\section{The $\mathrm{CP}$ and $\mathrm{AP}$ are responsible for the decreased serum survival of the cjrABC-sen $B$-expressing ExPEC}

The roles of the three complement pathways in the differential killing of $\mathrm{Cjr}^{+}-\mathrm{RS} 218$ and $\mathrm{Cjr}^{-}-\mathrm{RS} 218$ were investigated. The strains were independently incubated in $40 \%$ NHS and $40 \%$ NHS with a blocked CP (C1q-depleted serum), AP (factor B-depleted serum), or LP (mannose treated serum). After $3 \mathrm{~h}$ of incubation, the survival rates of each strain in these sera were determined. Then, the survival rate of $\mathrm{Cjr}^{-}$-RS218 in a serum was compared with that of $\mathrm{Cjr}^{+}$-RS218 in the same kind of serum. As shown in Fig. 3a, the survival rates of $\mathrm{Cjr}^{-}$RS218 were $24.8 \pm 4.7,1.1 \pm 0.2,1.5 \pm 0.1$, and $22.9 \pm 4.3$ fold greater than those of $\mathrm{Cjr}^{+}-\mathrm{RS} 218$ in normal (NHS), CP-blocked, AP-blocked, and LP-blocked sera, respectively. The fold difference of the bacterial survival in the $\mathrm{CP}$ - and AP-blocked sera was significantly lower than that in NHS, while the survival difference in NHS and the LP-blocked serum showed no statistical significance (Fig. 3a). When these sera were heat inactivated, $\mathrm{Cjr}^{+}-$ RS218 and $\mathrm{Cjr}^{-}$-RS218 showed similar survival rates

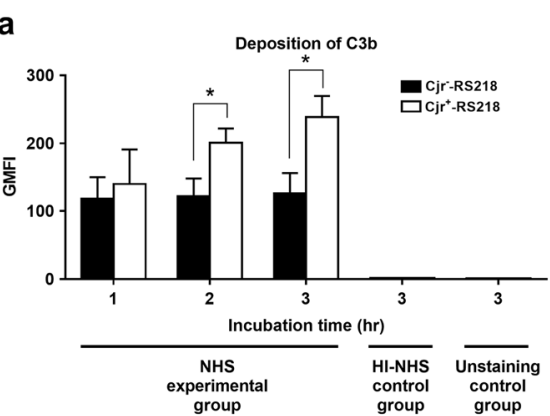

b

c

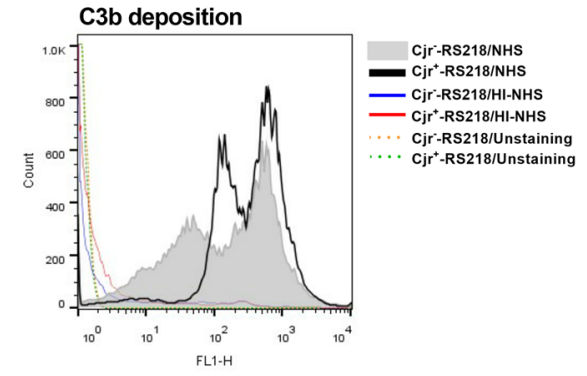

d
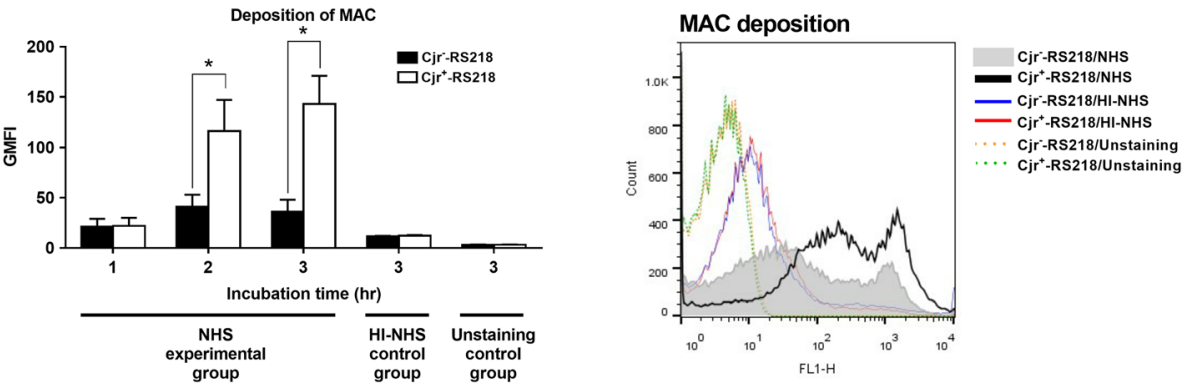

Fig. 2 Deposition of C3b and MAC on Cjr ${ }^{+}-\mathrm{RS} 218$ and $\mathrm{Cjr}^{-}-\mathrm{RS} 218$ in 40\% NHS for various periods. (a) Levels of C3b deposition on Cjr ${ }^{+}$-RS218 and $\mathrm{Cjr}^{-}$-RS218 after incubation with NHS for the indicated time periods. (b) Flow cytometry histogram of C3b deposition on the bacteria after $3 \mathrm{~h}$ of incubation in NHS. (c) Levels of MAC deposition on $\mathrm{Cjr}^{+}-\mathrm{RS} 218$ and $\mathrm{Cjr}^{-}-\mathrm{RS} 218$ after incubation with NHS for the indicated time periods. (d) Flow cytometry histogram of MAC deposition on the bacteria after $3 \mathrm{~h}$ of incubation in NHS. For (a) and (c) The data are presented with geometric mean fluorescence intensity (GMFI). The HI-NHS control groups were bacteria incubated in HI-NHS, while the unstaining control groups were the bacteria without fluorescence staining. The results are shown as the means \pm standard deviations, and the data are representative of three independent experiments performed in triplicate. ${ }^{*}$, $P$ value $<0.05$ 

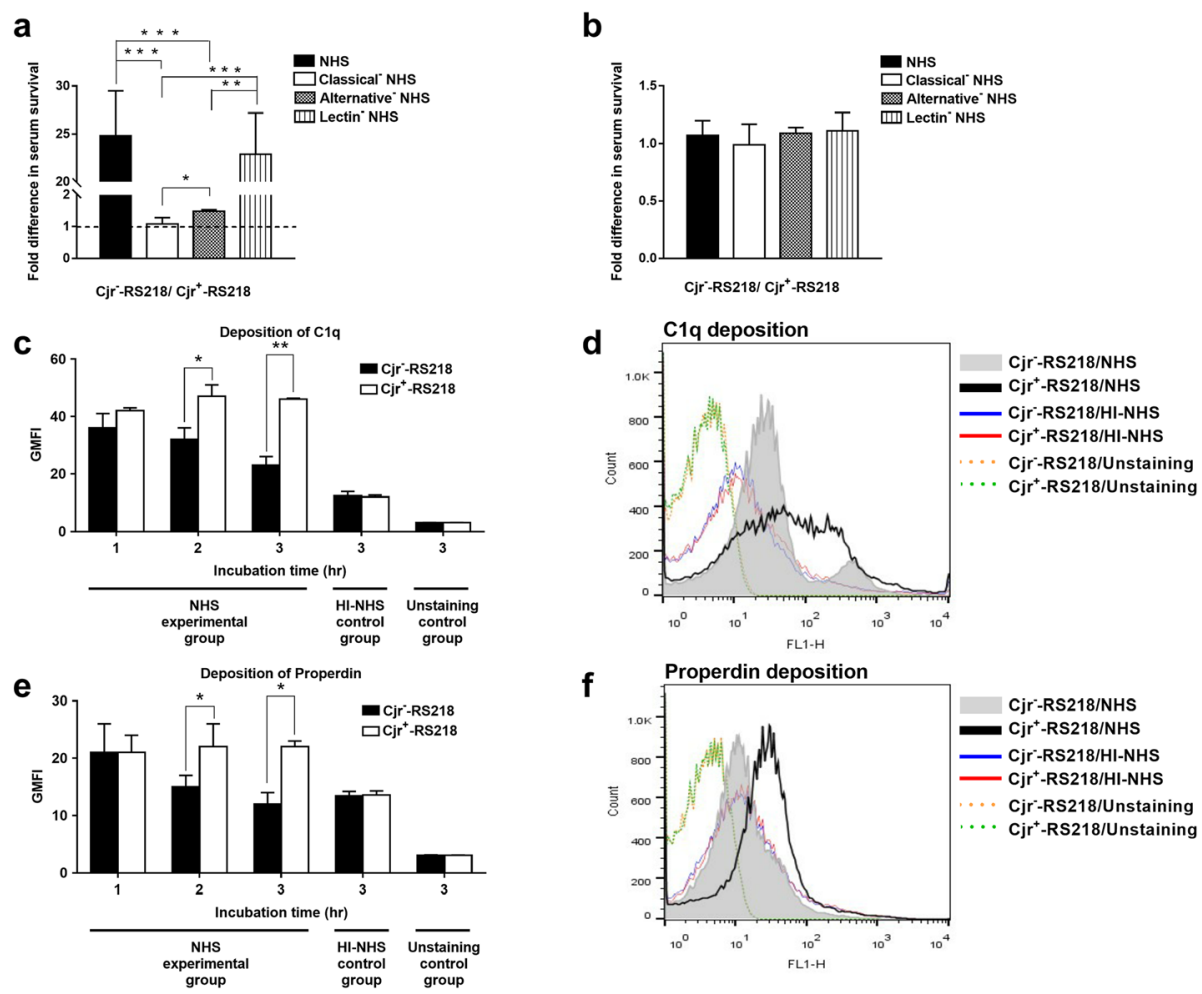

Fig. 3 The fold difference in the serum survival of $\mathrm{Cjr}^{-}$-RS218 compared to that of $\mathrm{Cjr}^{+}-\mathrm{RS} 218$ and the deposition of $\mathrm{Clq}$ and properdin on the

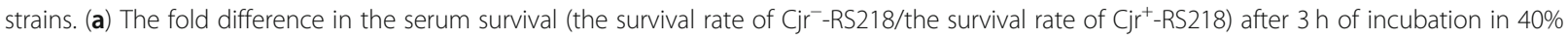
sera, which were NHS and NHS with the classical, alternative, or lectin pathway inhibited. The horizontal dashed line represents 1-fold (the survival of the two strains is similar). The serum survival of $\mathrm{Cjr}^{-}-\mathrm{RS} 218$ was approximately 24.8-, 1.1-, 1.5-, and 22.9-fold greater than that of Cjr ${ }^{+}$RS218 in NHS or NHS in which the classical, alternative, or lectin pathway was inhibited, respectively. (b) The fold difference in survival in $40 \% \mathrm{HI}$ NHS and 40\%-modified HI-NHS, in which the classical, alternative, or lectin pathway was inhibited. Cjr ${ }^{-}$-RS218 and Cjr-RS218 showed similar serum survival in these sera. For (a) and (b), the results are shown as the mean \pm standard deviation, and the data are representative of three independent experiments performed in triplicate. Classical ${ }^{-} \mathrm{NHS}, \mathrm{Clq}$-depleted NHS in which the CP is blocked; Alternative ${ }^{-} \mathrm{NHS}^{-}$factor Bdepleted NHS in which the AP is blocked; Lectin ${ }^{-}$NHS, mannose-treated NHS in which the LP is blocked; Classical ${ }^{-}$HI-NHS, heat-inactivated C1q- $^{-}$ depleted NHS; Alternative- HI-NHS, heat-inactivated factor B-depleted NHS; Lectin ${ }^{-}$HI-NHS, heat-inactivated mannose-treated NHS. (c) The levels of $\mathrm{Clq}$ deposition after incubation in 40\% NHS. (d) Flow cytometry histogram of C1q deposition on the bacteria after $3 \mathrm{~h}$ of incubation in NHS. (e) The levels of properdin deposition after incubation in 40\% NHS. (f) Flow cytometry histogram of properdin deposition on the bacteria after 3 h of incubation in NHS. For (c) and (e), the data are presented with GMFI. The results are shown as the means \pm standard deviations, and the data are derived from three independent experiments. The HI-NHS control groups were bacteria incubated in HI-NHS, while the unstaining control groups were the bacteria without fluorescence staining. ${ }^{*}, P$ value $<0.05 ;{ }^{* *}, P$ value $<0.01$; ${ }^{* * *}, P$ value $<0.001$

(Fig. 3b). In addition, it is known that anti-C1q and antiproperdin antibodies can block $\mathrm{CP}$ and $\mathrm{AP}$, respectively $[22,23]$. Consistently, the survival difference of $\mathrm{Cjr}^{+}-$ RS218 and $\mathrm{Cjr}^{-}$-RS218 in the serum treated with antiC1q antibody or anti-properdin antibody-treated sera was significantly lower that the difference in NHS (Additional file 1: Fig. S1). These results suggest that the complement-mediated differential killing of $\mathrm{Cjr}^{+}$-RS218 and $\mathrm{Cjr}^{-}-\mathrm{RS} 218$ in NHS is due to mainly CP- and APmediated bactericidal activity.

The above findings directed us to speculate that $\mathrm{Cjr}^{+}-$ RS218 may trigger stronger CP- and AP-mediated complement activation than $\mathrm{Cjr}^{-}-\mathrm{RS} 218$. In NHS, C1q binding to the bacteria initiates $\mathrm{CP}$ activation, while properdin is a positive regulator and an initiator of the
AP [35-37]. Thus, after incubation in serum, higher levels of $\mathrm{C} 1 \mathrm{q}$ and properdin deposition on the bacterial surface indicate that higher levels of $\mathrm{CP}$ and AP activation are triggered by the bacteria $[18,37]$. To investigate whether $\mathrm{Cjr}^{+}$-RS218 triggers higher levels of $\mathrm{CP}$ and $\mathrm{AP}$ activation than $\mathrm{Cjr}^{-}-\mathrm{RS} 218$ in NHS, the levels of C1q and properdin deposition on the bacteria were determined by flow cytometry after incubation with NHS. As shown in Fig. 3c, d, e, and f, $\mathrm{Cjr}^{+}-\mathrm{RS} 218$ exhibited significantly higher levels of $\mathrm{C} 1 \mathrm{q}$ and properdin deposition than $\mathrm{Cjr}^{-}$-RS218 after $2 \mathrm{~h}$ and $3 \mathrm{~h}$ of incubation in $40 \%$ NHS, suggesting that expression of $\operatorname{cj} A B C$-sen $B$ triggers stronger activation of the CP and AP in NHS.

In addition, it is known that ExPEC can actively suppress the activation of the complement system through 
recruiting host complement regulators on its surface. For example, ExPEC can recruit the $\mathrm{CP}$ regulator C4bp to block the activation of the CP [38], while the bacteria can recruit the AP regulator factor $\mathrm{H}(\mathrm{FH})$ to block the activation of the AP [39]. Thus, we investigated C4bp and $\mathrm{FH}$ deposition on $\mathrm{Cjr}^{+}-\mathrm{RS} 218$ and $\mathrm{Cjr}^{-}-\mathrm{RS} 218$. However, the strains showed similar deposition of the regulators (data not shown), suggesting that expression of $\operatorname{cj} A B C-\operatorname{sen} B$ does not affect ExPEC's ability to recruit the complement regulators.

\section{Expression of $c j r A B C$-sen $B$ triggers robust antibody- dependent $\mathrm{CP}$ activation}

The CP can be activated through direct binding of $\mathrm{C} 1 \mathrm{q}$ onto the bacteria or through antibody-dependent binding of $\mathrm{C} 1 \mathrm{q}$ by binding of this component to the antibody that has already bound to the bacteria. We investigated whether the expression of $\operatorname{cj} A B C-\operatorname{sen} B$ affects antibody-independent and antibody-dependent C1q deposition by flow cytometry analyses. In NHS, $\mathrm{Cjr}^{+}-\mathrm{RS} 218$ exhibited a significantly higher level of IgG binding than $\mathrm{Cjr}^{-}-\mathrm{RS} 218$ (Fig. 4a and b). However, after incubation with purified $\mathrm{C} 1 \mathrm{q}$, the two strains showed similar levels of C1q deposition (Fig. $4 \mathrm{c}$ and $\mathrm{d}$ ), in contrast to the above results showing that $\mathrm{Cjr}^{+}$-RS218 recruited higher levels of $\mathrm{C} 1 \mathrm{q}$ deposition in NHS in which IgG is present (Fig. 3c and $\mathrm{d}$ ). This result suggests that the expression of $\operatorname{cj} A B C-\operatorname{sen} B$ in ExPEC triggers stronger activation of the antibody-dependent $\mathrm{CP}$.

\section{Expression of $c j r A B C$-sen $B$ increases bacterial sensitivity to MAC-mediated attack}

To better understand why $\mathrm{Cjr}^{+}$-RS218 has lower serum survival, we further investigated whether $\mathrm{Cjr}^{+}$-RS218 is more vulnerable to the complement (MAC)-mediated attack than $\mathrm{Cjr}^{-}-\mathrm{RS} 218$ by assessing the survival of the two strains under the same level of MAC binding. For $\mathrm{Cjr}^{+}-\mathrm{RS} 218$ and $\mathrm{Cjr}^{-}-\mathrm{RS} 218$ to have a similar level of MAC deposition in the serum, we incubated the bacterial strains in different concentrations of NHS and determined the MAC deposition on the bacteria. We found that the MAC deposition level on $\mathrm{Cjr}^{+}$-RS218 incubated in $30 \%$ NHS was similar to that on $\mathrm{Cjr}^{-}-\mathrm{RS} 218$ incubated in $80 \%$ NHS (Fig. 5a and b), suggesting that $\mathrm{Cjr}^{+}$RS218 in 30\% NHS and $\mathrm{Cjr}^{-}-\mathrm{RS} 218$ in $80 \%$ NHS encounter a similar level of complement-mediated attack. As shown in Fig. 5c, the survival of $\mathrm{Cjr}^{+}-\mathrm{RS} 218$ in 30\% NHS was significantly lower than that of $\mathrm{Cjr}^{-}-\mathrm{RS} 218$ in $80 \%$ NHS, suggesting that $\mathrm{Cjr}^{+}-\mathrm{RS} 218$ is more vulnerable (susceptible) to the complement-mediated attack than $\mathrm{Cjr}^{-}-\mathrm{RS} 218$.

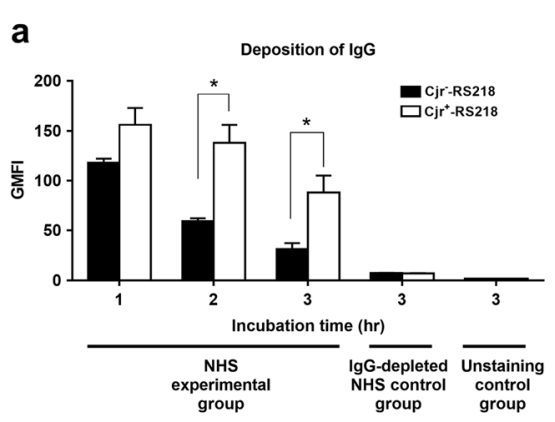

C

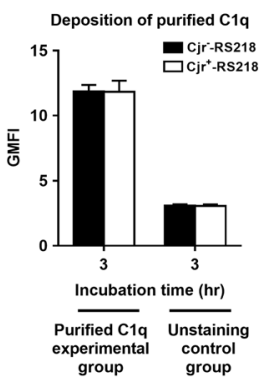

b

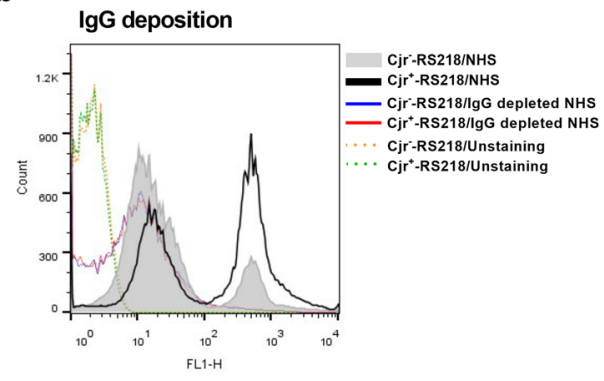

d

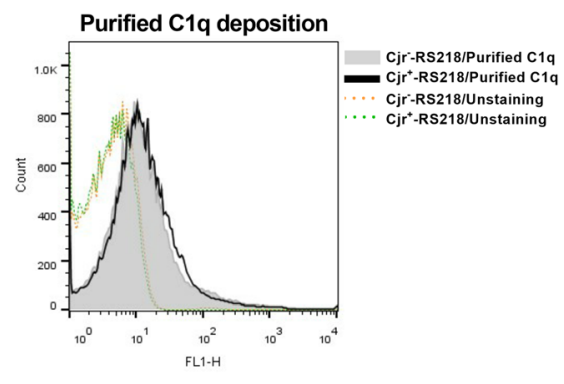

Fig. 4 The deposition of serum IgG and purified C1q proteins on $\mathrm{Cjr}^{+}-\mathrm{RS} 218$ and $\mathrm{Cjr}^{-}$-RS218. (a) Levels of IgG deposition on the indicated strains after incubation in $40 \% \mathrm{NHS}$. (b) Flow cytometry histogram of IgG deposition on the bacteria after $3 \mathrm{~h}$ of incubation in $40 \% \mathrm{NHS}$. (c) Levels of purified C1q protein on the indicated strains after incubation with a solution containing $32 \mu \mathrm{g} / \mathrm{ml} \mathrm{C1q} \mathrm{protein} \mathrm{for} 3 \mathrm{~h}$. (d) Flow cytometry histogram of C1q deposition on the bacteria after incubation with a solution containing $32 \mu \mathrm{g} / \mathrm{ml} \mathrm{C1q} \mathrm{protein} \mathrm{for} 3 \mathrm{~h}$. For (a) and (c), the data are derived from flow cytometry analyses and presented as GMFI. The lgG depleted-NHS control group was bacteria incubated in IgG depleted-NHS, while the unstaining control groups were the bacteria without fluorescence staining. ${ }^{*}, P$ value $<0.05$ 

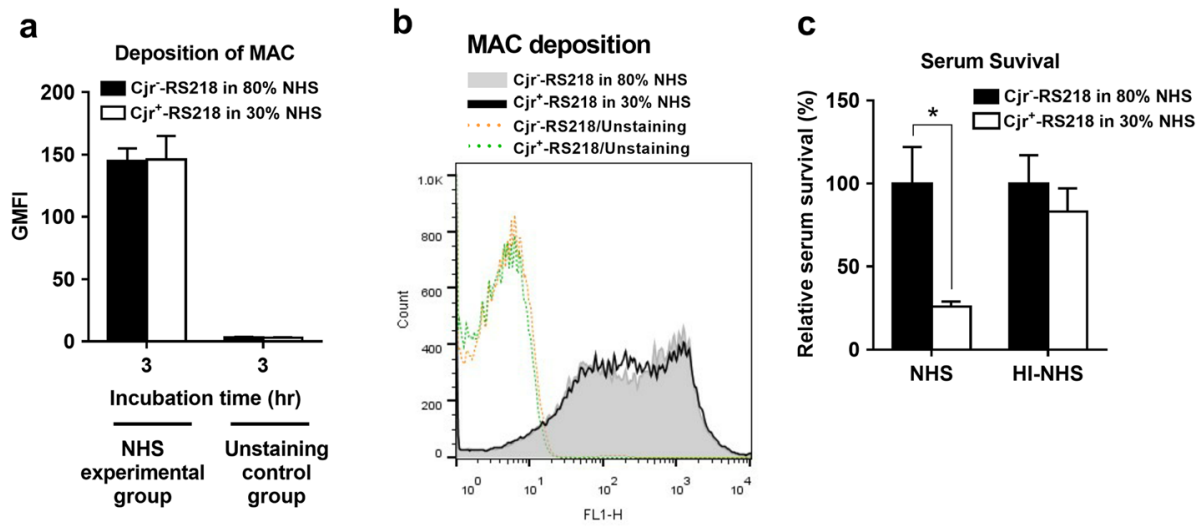

Fig. 5 The survival of $\mathrm{Cjr}^{-}-\mathrm{RS} 218$ and $\mathrm{Cjr}^{+}-\mathrm{RS} 218$ under a similar level of MAC-mediated attack in human serum. (a) $\mathrm{Cjr}^{-}-\mathrm{RS} 218 \mathrm{and} \mathrm{Cjr}^{+}-\mathrm{RS} 218$ showed a similar level of MAC binding to their surfaces after incubation with 80 and 30\% NHS, respectively, for $3 \mathrm{~h}$. The data are derived from flow cytometry analyses and presented as GMFI. The unstaining control group was the bacteria without fluorescence staining. (b) Flow cytometry histogram of MAC deposition on $\mathrm{Cjr}^{-}-\mathrm{RS} 218$ and $\mathrm{Cjr}^{+}-\mathrm{RS} 218$ after $3 \mathrm{~h}$ of incubation in 80 and $30 \% \mathrm{NHS}$, respectively. (c) The relative survival rates of $\mathrm{Cjr}^{-}-\mathrm{RS} 218$ and $\mathrm{Cjr}^{+}-\mathrm{RS} 218$ after incubation in 80\% serum (NHS or HI-NHS) and 30\% serum (NHS or HI-NHS), respectively, for $3 \mathrm{~h}$. The data are shown as the relative survival rates compared with those of $\mathrm{Cjr}^{-}-\mathrm{RS} 218$. The results are shown as the means \pm standard deviations, and the data are representative of three independent experiments performed in triplicate. ${ }^{*}, P$ value $<0.05$

\section{Bloodstream survival of RS218 strains with and without cjrABC-sen $B$ in cobra venom factor-treated mice}

To investigate whether complement contributes to the differential killing of RS218 strains with and without cjrABCsenB in vivo, we used cobra venom factor (CVF) to deplete complement activity in mice. The CVF treatment depleted approximately $85 \%$ of the complement activity in sera (data not shown). Equal amounts of $\mathrm{Cjr}^{-}-\mathrm{RS} 218$ and $\mathrm{Cjr}^{+}-\Delta$ lacZRS218 (the Cjr ${ }^{+}$-RS218 strain with a lac $Z$ deletion) were co-inoculated into mice pretreated with CVF or PBS. At 14 $\mathrm{h}$ post-inoculation, the blood counts of the $\mathrm{Cjr}^{-}$and $\mathrm{Cjr}^{+}$ bacteria were differentiated and determined by plating on LB agar containing IPTG and X-gal. The bacterial ratio $\left(\mathrm{Cjr}^{-} / \mathrm{Cjr}^{+}\right)$in the blood was normalized by the ratio in inoculum to calculate the competitive (CI). The CI in the CVF-treated mice was significantly lower than that in the PBS-treated mice (Fig. 6). This result indicates that depletion of complement activity significantly decreases the survival difference between the $\mathrm{Cjr}^{-}$and $\mathrm{Cjr}^{+}$bacteria in the bloodstream, suggesting that complement contributes to the differential killing of RS218 strains with and without cjr $A B C$-sen $B$ in vivo. Additionally, in the CVF-treated mice, the $\mathrm{CI}$ of $\mathrm{Cjr}^{-}$v.s. $\mathrm{Cjr}^{+}$was still higher than 1 in CVFtreated mice, suggesting that the $\mathrm{Cjr}^{-}$bacteria still exhibits a higher survival than the $\mathrm{Cjr}^{+}$bacteria in the animals. The residual complement activity or/and factors other than complement in the animals may contribute to the differential killing of the bacteria in the bloodstream.

\section{CjrA is responsible for the decreased serum survival of the cjrABC-sen $B$-expressing ExPEC}

Individual genes in $\operatorname{cj} r A B C$-sen $B$ were assessed for their contribution to the attenuated serum survival of ExPEC.
The RS218 strains CjrA-RS218, CjrB-RS218, CjrCRS218, and SenB-RS218, which express only CjrA, CjrB, $\mathrm{CjrC}$, or SenB, respectively (Table 1), were analyzed for their serum survival. CjrA-RS218 showed a significantly lower survival rate in NHS than $\mathrm{Cjr}^{-}$-RS218, while the strains expressing the other genes showed similar or even slightly higher NHS survival rates than $\mathrm{Cjr}^{-}-\mathrm{RS} 218$ (Fig. 7a). On the other hand, they showed similar survival rates in HI-NHS (Fig. 7b). This finding suggests that CjrA is the major protein responsible for the decreased serum survival of cjrABC-senB-expressing ExPEC. Based on its sequence, CjrA is a potential inner membrane (IM) lipoprotein. We consistently found that the CjrA protein is located in the IM fraction of ExPEC (Fig. 7c), suggesting that expression of CjrA in the IM may indirectly interfere with outer membrane $(\mathrm{OM})$ integrity, which affects the interaction between ExPEC and the complement system.

\section{The expression of $c j r A B C$-sen $B$ compromises outer membrane integrity}

The OM of E. coli is what the complement system interacts with. It has been shown that OM integrity is important for $E$. coli modulation of complement system activation [18, 23, 38, 39] and for E. coli resistance to complement-mediated attack [40]. Because an intact $\mathrm{OM}$ is required for bacteria to resist detergent [41, 42], the OM integrity of $\mathrm{Cjr}^{-}-\mathrm{RS} 218, \mathrm{Cjr}^{+}-\mathrm{RS} 218$, and CjrARS218 was measured through evaluating their detergent resistance. Equal amounts of the bacteria were inoculated into LB with or without different concentrations of SDS (0.01-5\%). After $2 \mathrm{~h}$ of incubation, we found that $\mathrm{Cjr}^{+}-\mathrm{RS} 218$ and CjrA-RS218 showed significantly lower 


\section{Bloodstream survival}

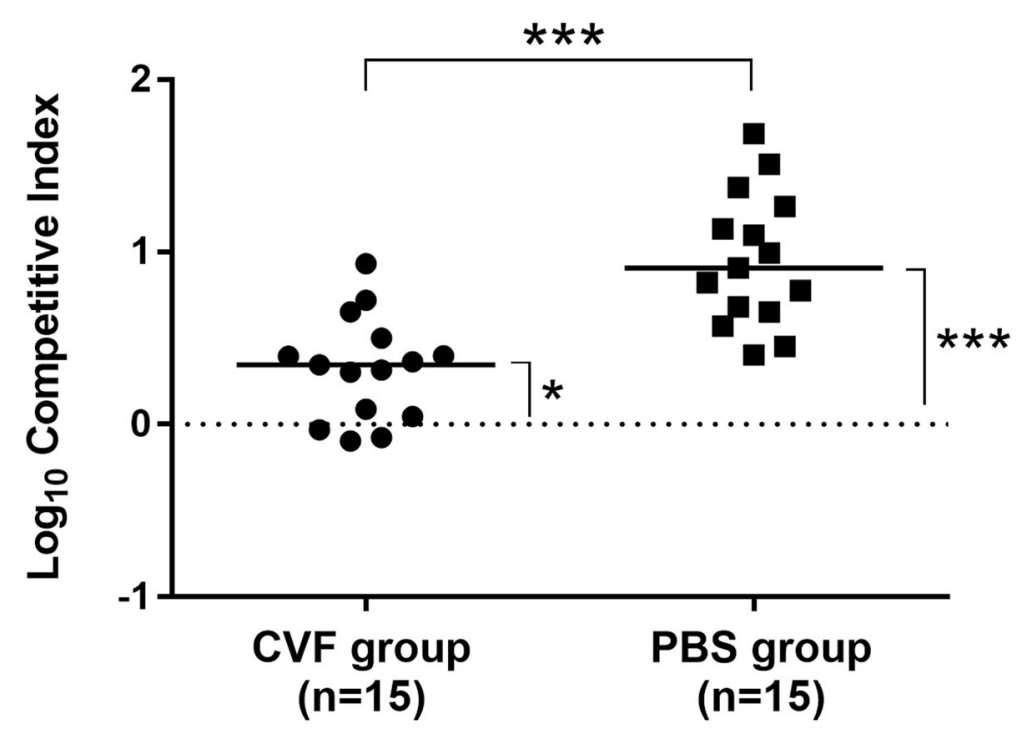

\section{$\mathrm{Cjr}^{-}-\mathrm{RS} 218$ v.s. $\mathrm{Cjr}^{+}-\Delta \mathrm{lacZ}-\mathrm{RS} 218$}

Fig. 6 The survival of RS218 strains with and without cjrABC-senB in the bloodstream of CVF-treated mice and PBS-treated mice. Equal numbers of $\mathrm{Cjr}^{-}-\mathrm{RS} 218$ and $\mathrm{Cjr}^{+}-\mathrm{AlacZ}$-RS218 were co-inoculated into mice pretreated with CVF or PBS. At $14 \mathrm{~h}$ post-inoculation, the competitive index (Cl) of $\mathrm{Cjr}^{-}-\mathrm{RS} 218$ v.S. Cjr ${ }^{+}-\mathrm{NaCZ}-\mathrm{RS} 218$ in the animals were determined. The $\mathrm{Cl}$ was calculated as follows: $\mathrm{Cl}=$ (bacterial counts of $\mathrm{Cjr}{ }^{-}-\mathrm{RS}_{218 / \mathrm{bacterial}^{-}}$ counts of $\mathrm{Cjr}^{+}-\mathrm{NaCZ}-\mathrm{RS} 218$ )/ (inoculum counts of $\mathrm{Cjr}^{-}$-RS218/inoculum counts of $\mathrm{Cjr}^{+}$-NacZ-RS218). The horizontal bars represent the median values. ${ }^{*}, P$ value $<0.05 ;{ }^{* *}, P$ value $<0.001$

turbidity $\left(\mathrm{OD}_{600}\right)$ than $\mathrm{Cjr}^{-}-\mathrm{RS} 218$ in the cultures with SDS, while they showed similar turbidity in LB (Fig. 8a). These results indicated that the detergent resistance of $\mathrm{Cjr}^{+}$-RS218 and CjrA-RS218 is significantly lower than that of $\mathrm{Cjr}^{-}-\mathrm{RS} 218$, thus suggesting that expressing CjrA or CjrABC-senB may interfere with OM integrity.

In addition, we assessed the abilities of these strains to retain periplasmic proteins, which reflects their $\mathrm{OM}$ integrity. A periplasmic RNase assay was performed [31-33]. When grown on RNase test agar plates (see Materials and Methods), RNase leakage from the periplasm formed pink halos around bacterial colonies. As shown in Fig. 8b, Cjr ${ }^{+}$-RS218 and CjrA-RS218 showed more significant leakage of periplasmic RNase than $\mathrm{Cjr}^{-}$RS218, consistently demonstrating that expression of $\operatorname{cjr} A B C-\operatorname{sen} B$ and $\operatorname{cjr} A$ compromises OM integrity.

The higher levels of periplasmic protein leakage of $\mathrm{Cjr}^{+}$-RS218 and CjrA-RS218 (Fig. 8b) suggest that expression of $\operatorname{cj} A B C-\operatorname{sen} B$ and $\operatorname{cjr} A$ increases OM permeability. OM permeability may affects the sensitivity of bacteria to some antibiotics (eg. Rifampicin). We measured the survival of $\mathrm{Cjr}^{-}-\mathrm{RS} 218, \mathrm{Cjr}^{+}-\mathrm{RS} 218$, and CjrARS218 in different concentration of rifampicin. As shown in Fig. 8c, the survival of $\mathrm{Cjr}^{+}-\mathrm{RS} 218$ and CjrARS218 was significantly lower than $\mathrm{Cjr}^{-}$-RS218 in the media containing $8 \mu \mathrm{g} / \mathrm{ml}$ and $16 \mu \mathrm{g} / \mathrm{ml}$ of rifampicin, suggesting that expression of $\operatorname{cj} A B C-\operatorname{sen} B$ and $\operatorname{cj} A$ may increase bacterial sensitivity to antibiotics.

Finally, we investigated whether $\operatorname{cjr} A B C$-sen $B$ expression affects the expression of the OM components LPS, OmpA, and NlpI and of the periplasmic protease Prc, which have been shown to contribute to ExPEC resistance to the host complement system [18, 23, 43, 44]. However, the expression levels of these factors were not significantly different in $\mathrm{Cjr}^{+}-\mathrm{RS} 218$ and $\mathrm{Cjr}^{-}-\mathrm{RS} 218$ (Additional file 2: Fig. S2a and S2b), suggesting that these bacterial factors are not involved in the decreased serum survival of the $\operatorname{cj} A B C$-sen $B$-expressing ExPEC strains.

The distribution of $c j r A B C$-sen $B$ in non-UTI-associated $E$. coli bacteremia isolates suggests that the gene cluster does not contribute to human non-UTI-associated bacteremia

In addition to demonstrating that $\operatorname{cj} A B C$-sen $B$ is epidemiologically associated with $E$. coli UTIs in humans, as mentioned in the "Introduction" section, our previous study, in contrast, shows that the distribution of $\operatorname{cj} A B C$ $\operatorname{sen} B$ is not associated with biliary tract infection (BTI)associated bacteremia, suggesting that $\operatorname{cj} A B C$-sen $B$ does not contribute to BTI-associated ExPEC bacteremia in humans [5]. To further investigate whether $\operatorname{cj} A B C-\operatorname{sen} B$ 

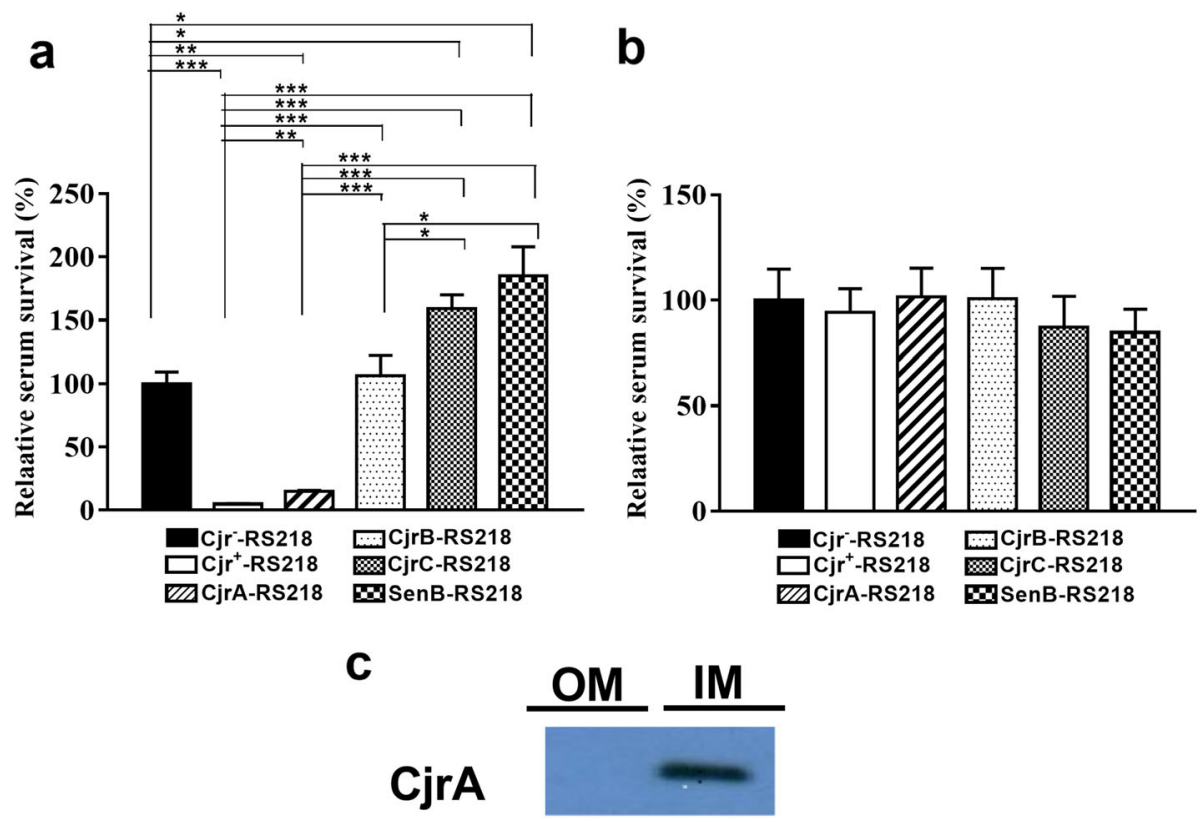

\section{OmpA}

Fig. 7 Survival of the RS218 strains harboring individual genes of the cjrABC-senB gene cluster in NHS or HI-NHS and localization of CjrA. (a) and (b) The survival rates of the bacterial strains were determined after the strains were incubated for $3 \mathrm{~h}$ in $40 \% \mathrm{NHS}$ (a) or $40 \% \mathrm{HI}-\mathrm{NHS}$ (b). The data are shown as relative survival rates compared with those of $\mathrm{Cjr}^{-}-\mathrm{RS} 218$. The results are shown as the means \pm standard deviations, which are representative of three independent experiments performed in triplicate. (c) The localization of CjrA. The outer and inner membrane (OM and IM) fractions of CjrA-RS218, which expresses C-terminally His ${ }_{6}$-tagged CjrA, were isolated and subjected to Western blot analysis with an anti-His ${ }_{6}$ antibody or OmpA antiserum. OmpA serves as an OM marker. ${ }^{*}, P$ value $<0.05$

is involved in non-UTI-associated and non-BTIassociated bacteremia in humans, $48 \mathrm{E}$. coli bacteremia isolates that are not associated with UTI and BTI were collected and designated non-UBTI bacteremia isolates. The distribution rate of $\operatorname{cj} A B C-\operatorname{sen} B$ in the non-UBTI group was determined by PCR. Then, the resulting distribution rate was compared with that in fecal and UTI-associated (cystitis-, pyelonephritis-, and urosepsisassociated) isolates. The distribution rates in the fecal and UTI-associated groups were quoted from the previous study [5]. As shown in Table 2, the frequency of $\operatorname{cj} A B C-\operatorname{sen} B$ in the non-UBTI-associated group of isolates was $17 \%$. The frequency in these isolates was significantly lower than those in the UTI-associated isolates, while the distribution showed no significant difference between this group and the fecal group. In combination with the previous finding that $\operatorname{cj} A B C-\operatorname{sen} B$ is not associated with BTI-associated bacteremia, these findings suggest that $\operatorname{cj} A B C$-sen $B$ does not contribute to non-UTI-associated bacteremia (bacteremia not associated with UTIs) in humans. These epidemiological findings are in agreement with the results derived from the mouse model of bacteremia and human serum survival assays in the present study.

\section{Discussion}

In this study, we demonstrated that $\operatorname{cj} A B C-\operatorname{sen} B$, which has been previously shown to contribute to the pathogenesis of E. coli UTIs, hinders ExPEC bloodstream survival. Expression of this gene cluster decreased the pathogen's ability to resist serum-mediated killing. In NHS, bacteria with $\operatorname{cjr} A B C-\operatorname{sen} B$ encountered a stronger complement-mediated attack than those without the gene cluster because the harboring strains triggered stronger activation of the complement system through the AP and antibody-dependent CP. Additionally, expression of $\operatorname{cj} A B C-\operatorname{sen} B$ increased the pathogen's susceptibility to complement-mediated attack. Thus, the complement system was responsible for the decreased ability of the $\operatorname{cj} A B C$-sen $B$-expressing ExPEC to survive in the bloodstream. Consistently, the molecular epidemiological investigation showed that the distribution of $\operatorname{cj} A B C-\operatorname{sen} B$ was not associated with $E$. coli-caused human bacteremia, although it has been previously shown to be associated with $E$. coli-caused human UTIs.

$\operatorname{cj} A B C-\operatorname{sen} B$ plays niche-dependent and contradictory roles in the pathogenesis of ExPEC because it contributes to ExPEC UTIs [4] but hinders the bacteria from causing bacteremia. Bacterial virulence factors with 


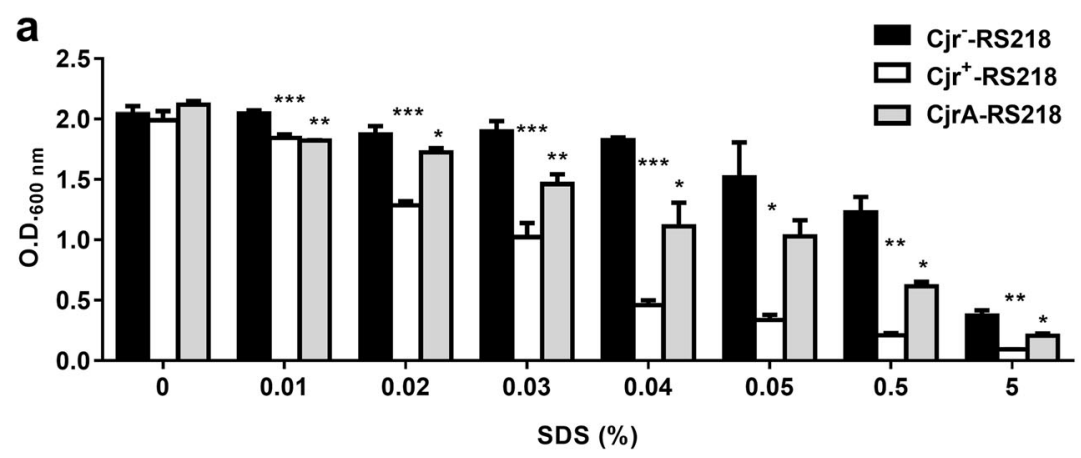

b

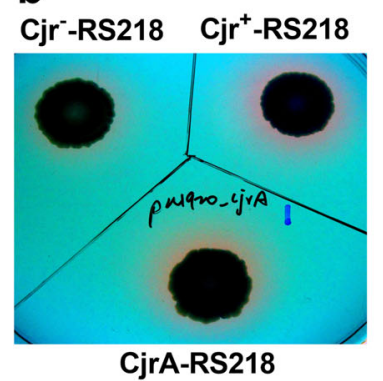

C

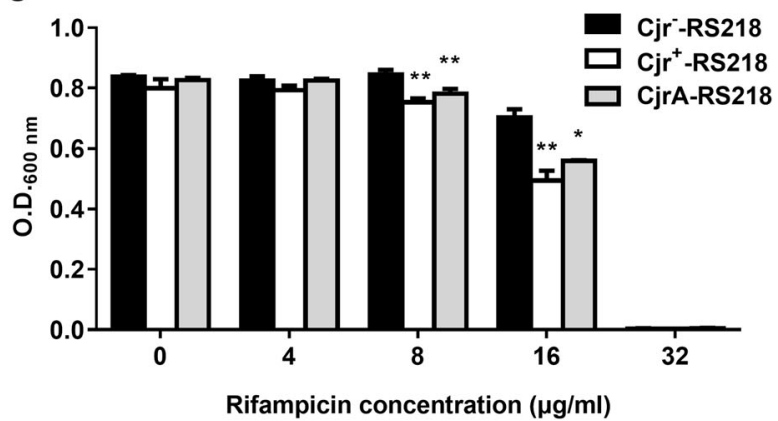

Fig. 8 The effects of cjrABC-senB expression on the OM properties of the E. coli strain RS218. (a) SDS sensitivity assays of Cjr ${ }^{-}-R_{S} 218, \mathrm{Cjr}^{+}-\mathrm{RS} 218$, and Cjr-RS218. The bacterial cultures were adjusted to O.D.600 $=1$ in LB with different concentrations of SDS. After $2 \mathrm{~h}$ of incubation at $37^{\circ} \mathrm{C}$, the turbidity (O.D.600) of each bacterial culture was determined. (b) An RNase assay with Cjr ${ }^{-}$-RS218, Cjr ${ }^{+}$-RS218, and CjrA-RS218. The bacteria were grown on an RNase test agar plate. The pink halos around the colonies indicate the leakage of periplasmic RNase into the agar. (c) Rifampicin sensitivity assay. Cjr ${ }^{-}-\mathrm{RS} 218$, $\mathrm{Cjr}^{+}-\mathrm{RS} 218$, and CjrA-RS218 $\left(5 \times 10^{5} \mathrm{CFU} / \mathrm{ml}\right)$ were cultured in Mueller-Hinton broth containing different concentrations of rifampicin in a 96 well plate $\left(200 \mu \mathrm{l} /\right.$ well). After $8 \mathrm{~h}$ of incubation at $37^{\circ} \mathrm{C}$, the turbidity (O.D.600) of each bacterial culture was determined. For $(\mathbf{a})$ and $(\mathbf{c})$ the results are shown as the mean \pm standard deviation, and the data are representative of three independent experiments performed in triplicate. The asterisks indicate significant differences ( ${ }^{*}, P$ value $<0.05 ;{ }^{*}, P$ value $<0.01 ; *^{* *}, P$ value $\left.<0.001\right)$ between the O.D.600 value of the indicated strain and that of $\mathrm{Cjr}^{-}{ }^{-} \mathrm{RS} 218$

similar properties have been reported in other pathogenic bacteria. For example, the PilU protein of Neisseria meningitidis contributes to the microcolony formation of the pathogen on host epithelial cells, which is the essential pathogenic step to initiate infection, while expression of this protein decreases the pathogen's ability to survive in NHS [45]. Additionally, the capsule of Klebsiella pneumoniae is known to contribute to bacterial resistance to serum killing and phagocytosis, whereas the capsule impedes pathogen binding to and invasion of epithelial cells [46]. These findings suggest that bacterial virulence factors with niche-dependent and contradictory roles are broadly present in various bacterial pathogens. Identification and understanding of such bacterial factors would help in the development of more precise and efficient therapeutic and preventive measures when utilizing virulence factors as anti-infection targets.

Several studies have suggested that the complement system facilitates ExPEC to cause UTIs, although some other studies have shown that the complement system is functional in urinary tracts (UTs) and thus supposed to facilitate the clearance of invading pathogens in UTs [47-51]. It is reported that mice deficient of the C3

Table 2 Distributio of cjrABC-senB in different source groups of E. coli isolates

\begin{tabular}{|c|c|c|c|c|c|c|c|c|c|}
\hline \multirow[t]{2}{*}{ Gene } & \multicolumn{5}{|l|}{ No. (\%) of E. coli isolates } & \multicolumn{4}{|l|}{$p^{a}$} \\
\hline & $\begin{array}{l}\text { Non-UBTI bacteremia }{ }^{b} \\
(n=47)\end{array}$ & $\begin{array}{l}\text { Fecal isolates } \\
(n=115)\end{array}$ & $\begin{array}{l}\text { Cystitis isolates } \\
(n=67)\end{array}$ & $\begin{array}{l}\text { Pyelonephritis isolates } \\
(n=72)\end{array}$ & $\begin{array}{l}\text { Urosepsis isolates } \\
(n=64)\end{array}$ & $\begin{array}{l}\text { Non- } \\
\text { UBTI } \\
\text { vs } \\
\text { Fecal }\end{array}$ & $\begin{array}{l}\text { Non- } \\
\text { UBTI vs } \\
\text { Cystitis }\end{array}$ & $\begin{array}{l}\text { Non-UBTI vs } \\
\text { Pyelonephritis }\end{array}$ & $\begin{array}{l}\text { Non- } \\
\text { UBTI vs } \\
\text { Urosepsis }\end{array}$ \\
\hline $\begin{array}{l}\text { cjrABC- } \\
\operatorname{sen} B\end{array}$ & $8(17)$ & $23(20)$ & $24(36)$ & $32(44)$ & $23(36)$ & - & 0.035 & 0.003 & 0.033 \\
\hline
\end{tabular}

${ }^{a}$ Only $P$ values $<0.05$ (by Fisher's exact test) are shown

b "Non-UBTI bacteremia" indicates bacteremia isolates that are not associated with UTIs or BTIs 
component are resistant to $E$. coli colonization of upper UTs [52]. In addition, opsonization of ExPEC by C3 promotes bacterial binding and invasion of uroepithelial cells [48]. Invasion of uroepithelial cells lining the UTs enhances the survival of infecting $E$. coli by providing protection from host immunity and enable the bacteria to invade into deeper tissues [48]. Given that $\operatorname{cj} r A B C$ $\operatorname{sen} B$ facilitates ExPEC colonization of UTs [4] and the distribution of the gene cluster is associated with UTIs (Table 2) [5], the cjrABC-senB-induced complement deposition may facilitate $E$. coli to cause UTIs. Li et al. have shown that although the maximum $\mathrm{C} 3$ concentration in the urine collected from patients with UTIs is about $1.4 \%$ of the C3 concentration in serum. The urine C3 concentration is shown to be sufficient to opsonize E. coli in UTs [48]. However, the low C3 concentration in urine suggests that the complement-mediated bactericidal activity in UTs would be significantly lower than that in the serum. It is likely that in UTs $\operatorname{cjr} A B C-\operatorname{sen} B$ expressing $E$. coli is benefited from the $\mathrm{C} 3$ oposonization for binding and invading uroepithelium in UTI, while the effect of the cjrABC-senB-raised complementmediated killing on the bacteria is neglectable.

Our results suggest that $\mathrm{Cjr}^{+}-\mathrm{RS} 218$ can recruit higher levels IgG and properdin deposition, and thus trigger higher levels of $\mathrm{CP}$ and $\mathrm{AP}$ activation, in comparison with $\mathrm{Cjr}^{-}$-RS218. Given that the OM is where the complement system initiate its activation, the compromised $\mathrm{OM}$ integrity and increased $\mathrm{OM}$ permeability caused by cjr $A B C$-sen $B$ expression may increase the accessibility of bacterial targets of serum IgG and properdin, enabling higher levels of IgG and properdin binding on bacterial surface and thus triggering higher levels of antibodydependent $\mathrm{CP}$ activation and AP activation. Consistently, a similar mechanistic pattern was found in one of our previous studies showing that a Prc protease mutation of $E$. coli induces compromised OM integrity and increased OM permeability [18]. The Prc mutant can also trigger a higher level of antibody-dependent $\mathrm{CP}$ activation in NHS.

In addition, the $\operatorname{cj} A B C$-sen $B$-induced interference in the $\mathrm{OM}$ integrity may be responsible for the lower survival of $\mathrm{Cjr}^{+}-\mathrm{RS} 218$ in comparison with that of $\mathrm{Cjr}^{-}$RS218 under a similar level of MAC-mediated attack (Fig. 5c). The OM of E. coli is where the complement exerts bactericidal activity. It is known that MACmediated bactericidal effect occurs through disrupting the $\mathrm{OM}$ of $E$. coli, thereby increasing the OM permeability and consequently inducing lethal changes in the inner membrane $[53,54]$. The increased OM permeability in $\mathrm{Cjr}^{+}-\mathrm{RS} 218$ may facilitate MAC-mediated bactericidal activity, thus increasing the vulnerability (susceptibility) of the $\operatorname{cj} A B C$-sen $B$-expressing bacteria to the MAC-mediated attack.
CjrA was located in the IM fraction of E. coli, but its expression affected OM integrity (Fig. 7c). Some IM proteins are known to be involved in maintaining the $\mathrm{OM}$ integrity of E. coli. For example, the IM proteins TolA, TolQ, and TolR interact with the Pal and TolB proteins to form the Tol-Pal protein complex, which spans the periplasm to link the inner and outer membranes [55]. The intact Tol-Pal complex is required to stabilize the OM. Thus, deletion of these IM proteins compromises OM integrity [56]. It is likely that CjrA may affect OM integrity through interfering with the function of other IM proteins that contribute to OM integrity.

Although among the $\operatorname{cjr} A B C-\operatorname{sen} B$ genes, $\operatorname{cjr} A$ is the main factor causing the compromised OM integrity of ExPEC, it may not be fully responsible for the impaired integrity. CjrA-RS218 showed a higher level of SDS resistance than $\mathrm{Cjr}^{+}$-RS218 (Fig. 8a), suggesting that, in addition to $\operatorname{cj} A$, other genes in the $\operatorname{cj} A B C-\operatorname{sen} B$ gene cluster also contribute to the compromised OM integrity. The subcellular localization of $\mathrm{CjrB}$ and $\mathrm{CjrC}$ suggests their potential contribution to the compromised OM integrity. CjrB shows significant similarities to TonB and thus is predicted to be a periplasm-exposed IM protein [28]. It is likely that the presence of CjrB in the IM affects the OM integrity in a way similar to that of CjrA. As $\mathrm{CjrC}$ is predicted to be an OM protein [28], the presence of CjrA in the OM may directly interfere with the $\mathrm{OM}$ structure and thus impair the membrane integrity. $\operatorname{sen} B$ is proposed to play a role in enterotoxin production of enteroinvasive $E$. coli [28]. Its involvement in interfering with the $\mathrm{OM}$ integrity cannot be excluded. Additionally, E. coli expressing the whole gene cluster $\left(\mathrm{Cjr}^{+}\right.$-RS218) showed significantly lower serum survival than E. coli expressing only CjrA (CjrA-RS218). However, expressing $\mathrm{CjrB}, \mathrm{CjrC}$, and $\mathrm{SenB}$, respectively, did not decrease bacterial survival in the serum (Fig. 7a). These results suggest that the combined effect of expressing all or multiple of the $\operatorname{cj} A B C-\operatorname{sen} B$ genes may be required to induce a level of interference with the $\mathrm{OM}$ integrity high enough to further decrease the ability of serum survival, in addition to the effect caused by CjrA alone.

Several lines of evidence suggest that the $\operatorname{cj} A B C-\operatorname{sen} B$ gene cluster encodes an iron-uptake system. In addition to the fact that the encoding proteins of the gene cluster are homologous to iron uptake-related proteins (see Introduction), a functional fur box is located upstream of $\operatorname{cjr} A B C-\operatorname{sen} B$, and the expression of $\operatorname{cjr} A B C-\operatorname{sen} B$ is negatively regulated by iron [28], which is a typical irondependent regulation mode of iron uptake systems in bacteria [57]. In addition, $\mathrm{CjrB}$ and $\mathrm{CjrC}$ are known to be involved in colicin Js uptake and are consequently essential for colicin Js sensitivity [28]. It has been known that iron uptake systems are employed to import colicins 
into sensitive bacterial strains [58]. These findings all indicate that $\operatorname{cj} A B C-\operatorname{sen} B$ encodes a potential iron uptake system. However, it remains to be further confirmed whether $\operatorname{cj} A B C-\operatorname{sen} B$ facilitates iron uptake.

\section{Conclusions}

Bacterial factors, such as $\operatorname{cj} A B C-\operatorname{sen} B$, with contradictory niche-dependent pathogenic roles may contribute to the development of novel antimicrobial strategies with which we may directly interfere with the proper expression of virulence factors to achieve an antimicrobial effect. For example, increasing $\operatorname{cj} A B C-\operatorname{sen} B$ expression in ExPEC may facilitate host elimination of invading ExPEC in the bloodstream. In addition, knowledge of the niche specificity of virulence factors is critical for developing efficient antimicrobial strategies using virulence factors as antimicrobial targets because this knowledge provides information concerning when and where the antivirulence strategy would be the most effective. However, given that most ExPEC virulence genes exist in only a portion of the ExPEC strains and that none of the virulence factors alone is sufficient to account for the virulence properties of the pathogens, an effective and widely usable strategy against ExPEC infections may require a combination of multiple virulence factors as targets. Thus, it is necessary to identify additional virulence factors and understand where and how they contribute to infections.

\section{Supplementary information}

Supplementary information accompanies this paper at https://doi.org/10. 1186/s12929-020-00677-4.

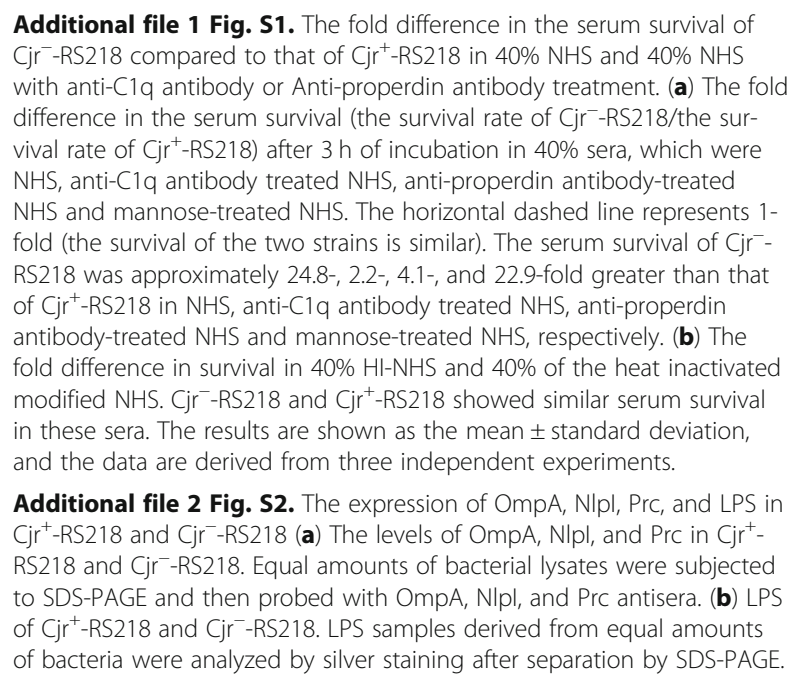

Additional file 2 Fig. S2. The expression of OmpA, NIpl, Prc, and LPS in $\mathrm{Cjr}^{+}-\mathrm{RS} 218$ and $\mathrm{Cjr}^{-}-\mathrm{RS} 218$ (a) The levels of OmpA, NIpl, and PrC in $\mathrm{Cjr}^{+}-$ RS218 and Cjr--RS218. Equal amounts of bacterial lysates were subjected to SDS-PAGE and then probed with OmpA, NIpl, and Prc antisera. (b) LPS of $\mathrm{Cjr}^{+}-\mathrm{RS} 218$ and $\mathrm{Cjr}^{-}$-RS218. LPS samples derived from equal amounts of bacteria were analyzed by silver staining after separation by SDS-PAGE.

\section{Abbreviations}

ExPEC: Extraintestinal pathogenic E. coli; UTIs: Urinary tract infections; MACs: Membrane attack complexs; CP: Classical pathway; AP: Alternative pathway; LP: Lectin pathway; CSF: Cerebrospinal fluid; PCR: Polymerase chain reaction; BTIs: Biliary tract infections; NHS: Normal human serum; HI-
NHS: Heat-inactivated NHS; CFU: Colony-forming unit; LB: Luria Bertani; IACUC: Institutional Animal Care and Use Committee; DIP: 2, 2'-dipyridyl; PBS: Phosphate buffered saline; LPS: Lipopolysaccharides; hr.: Hour; IM: Inner membrane; OM: Outer membrane; Cl: Competitive index; GMFI: Geometric mean fluorescence intensity; CVF: Cobra venom factor

\section{Acknowledgments \\ Not applicable.}

\section{Authors' contributions}

WCH, YJL, QFC and PCH carried out the experiments in this study. WCH, MH, and $\mathrm{CHT}$ contributed to the study conception, planning experiments, data analysis and interpretation. CSC and SYW participated in the result discussion and technical support. WCH and CHT wrote the manuscript. All authors read and approved the final manuscript.

\section{Funding}

This study was supported by Ministry of Science and Technology, Taiwan (grants MOST 108-2320-B-006-034-MY3, MOST 104-2320-B-006-003, and NSC 102-2628-B-006-004-MY3) and National Cheng Kung University Hospital, Taiwan (grant NCKUH-10301001). The funders had no role in study design, data collection and analysis, decision to publish, or preparation of the manuscript.

\section{Availability of data and materials}

All data and materials are fully available and are shown within the manuscript.

\section{Ethics approval}

All animal studies were performed according to the guideline by Council of Agriculture Executive Yuan Guideline for the Care and Use of Laboratory Animals, Republic of China. All of the animal experimental procedures were reviewed and approved by the Institutional Animal Care and Use Committee (IACUC) of National Cheng Kung University, Tainan City, Taiwan (Approval number. 99228). The procedures for collecting blood were approved by the Institutional Reviewer Board of National Cheng Kung University Hospital, Tainan City, Taiwan (IRB No. B-ER-101-361).

\section{Consent for publication}

Not applicable.

\section{Competing interests}

The authors do not have any commercial or other association that might pose a conflict of interest.

\section{Author details}

${ }^{1}$ Institute of Molecular Medicine, College of Medicine, National Cheng Kung University, 4th F, 367 Sheng Li Road, North District, Tainan City, Taiwan. ${ }^{2}$ Institute of Basic Medical Sciences, College of Medicine, National Cheng Kung University, Tainan City, Taiwan. ${ }^{3}$ Center of Infectious Disease and Signaling Research, National Cheng Kung University, Tainan City, Taiwan. ${ }^{4}$ Department of Microbiology, Immunology, and Biopharmaceuticals, National Chiayi University, Chiayi City, Taiwan. ${ }^{5}$ Department of Microbiology and Immunology, College of Medicine, National Cheng Kung University, Tainan City, Taiwan. 'Department of Biotechnology and Bioindustry Sciences, College of Bioscience and Biotechnology, National Cheng Kung University, Tainan City, Taiwan.

Received: 27 October 2019 Accepted: 28 July 2020

Published online: 06 August 2020

References

1. Mellata M. Human and avian extraintestinal pathogenic Escherichia coli: infections, zoonotic risks, and antibiotic resistance trends. Foodborne Pathog Dis. 2013;10(11):916-32.

2. Broaders E, Gahan CG, Marchesi JR. Mobile genetic elements of the human gastrointestinal tract: potential for spread of antibiotic resistance genes. Gut Microbes. 2013;4(4):271-80

3. Pitout JD. Extraintestinal pathogenic Escherichia coli: an update on antimicrobial resistance, laboratory diagnosis and treatment. Expert Rev Anti-Infect Ther. 2012;10(10):1165-76. 
4. Cusumano CK, Hung CS, Chen SL, Hultgren SJ. Virulence plasmid harbored by uropathogenic Escherichia coli functions in acute stages of pathogenesis. Infect Immun. 2010;78(4):1457-67.

5. Mao BH, Chang YF, Scaria J, Chang CC, Chou LW, N T., Wu JJ, Tseng CC, Wang MC, Chang CC, Hsu YM and Teng CH. Identification of Escherichia coli genes associated with urinary tract infections. J Clin Microbiol 50(2):449456, 2012.

6. Wijetunge DS, Karunathilake KH, Chaudhari A, Katani R, Dudley EG, Kapur V, DebRoy C, Kariyawasam S. Complete nucleotide sequence of pRS218, a large virulence plasmid, that augments pathogenic potential of meningitisassociated Escherichia coli strain RS218. BMC Microbiol. 2014;14:203.

7. Henderson JP, Crowley JR, Pinkner JS, Walker JN, Tsukayama P, Stamm WE, Hooton TM, Hultgren SJ. Quantitative metabolomics reveals an epigenetic blueprint for iron acquisition in uropathogenic Escherichia coli. PLoS Pathog. 2009;5(2):e1000305.

8. Seed PC, Hultgren SJ. Blueprinting the regulatory response of Escherichia coli to the urinary tract. Trends Microbiol. 2005;13(6):246-8.

9. Chan A.C., Lelj-Garolla B., F I.R., Pedersen K.A., Mauk A.G. and Murphy M.E. Cofacial heme binding is linked to dimerization by a bacterial heme transport protein. Journal of molecular biology 362(5):1108-1119, 2006.

10. Aisen $P$, Enns $C$, Wessling-Resnick M. Chemistry and biology of eukaryotic iron metabolism. Int J Biochem Cell Biol. 2001;33(10):940-59.

11. Skaar EP. The battle for iron between bacterial pathogens and their vertebrate hosts. PLoS Pathog. 2010;6(8):e1000949.

12. Walport MJ. Complement. First of two parts The New England journal of medicine. 2001;344(14):1058-66.

13. Achtman M, Mercer A, Kusecek B, Pohl A, Heuzenroeder M, Aaronson W, Sutton A and Silver RP. Six widespread bacterial clones among Escherichia coli K1 isolates. 39 1:315-335., 1983.

14. Cole BK, Scott E, llikj M, Bard D, Akins DR, Dyer DW, Chavez-Bueno S. Route of infection alters virulence of neonatal septicemia Escherichia coli clinical isolates. PLoS One. 2017;12(12):e0189032.

15. Day M.W., Jackson L.A., Akins D.R., Dyer D.W. and Chavez-Bueno S. WholeGenome Sequences of the Archetypal K1 Escherichia coli Neonatal Isolate RS218 and Contemporary Neonatal Bacteremia Clinical Isolates SCB11, SCB12, and SCB15. Genome Announc 3(1), 2015.

16. Silver RP, Aaronson W, Sutton A, Schneerson R. Comparative analysis of plasmids and some metabolic characteristics of Escherichia coli K1 from diseased and healthy individuals. Infect Immun. 1980;29(1):200-6.

17. Teng $\mathrm{CH}$, Tseng YT, Maruvada R, Pearce D, Xie Y, Paul-Satyaseela M, Kim KS. $\mathrm{NIpl}$ contributes to Escherichia coli K1 strain RS218 interaction with human brain microvascular endothelial cells. Infect Immun. 2010;78(7):3090-6.

18. Wang CY, Wang SW, Huang WC, Kim KS, Chang NS, Wang YH, Wu MH and Teng CH. Prc contributes to Escherichia coli evasion of classical complement-mediated serum killing. Infection and immunity, 2012, pp. 3399-3409.

19. Lerner CG, Inouye M. Low copy number plasmids for regulated low-level expression of cloned genes in Escherichia coli with blue/white insert screening capability. Nucleic Acids Res. 1990;18(15):4631.

20. Datsenko KA, Wanner BL. One-step inactivation of chromosomal genes in Escherichia coli K-12 using PCR products. Proc Natl Acad Sci U S A. 2000; 97(12):6640-5.

21. Huang WC, Lin CY, Hashimoto M, Wu JJ, Wang MC, Lin WH, Chen CS, Teng $\mathrm{CH}$. The role of the bacterial protease Prc in the uropathogenesis of extraintestinal pathogenic Escherichia coli. J Biomed Sci. 2020;27(1):14

22. Gupta-Bansal R, Parent JB, Brunden KR. Inhibition of complement alternative pathway function with anti-properdin monoclonal antibodies. Mol Immunol. 2000;37(5):191-201.

23. Tseng YT, Wang SW, Kim KS, Wang YH, Yao Y, Chen CC, Chiang CW, Hsieh PC, Teng CH. Nlpl facilitates deposition of C4bp on Escherichia coli by blocking classical complement-mediated killing, which results in high-level bacteremia. Infect Immun. 2012;80(10):3669-78.

24. Petersen SV, Thiel S, Jensen L, Vorup-Jensen T, Koch C, Jensenius JC. Control of the classical and the MBL pathway of complement activation. Mol Immunol. 2000;37(14):803-11.

25. Lin YC, Liao YJ, Lee YH, Tseng SF, Liu JY, Chen YS, Shui HA, Lin FZ, Lin KH, Chen YC, Tsai MC, Sytwu HK, Wang CC, Chuang YP. Staphylococcal phosphatidylinositol-specific phospholipase C potentiates lung injury via complement sensitisation. Cell Microbiol. 2019;21(10):e13085.

26. Costabile M. Measuring the $50 \%$ haemolytic complement (CH50) activity of serum. J Vis $\operatorname{Exp}$ (37), 2010.
27. Ratelade J, Verkman AS. Inhibitor(s) of the classical complement pathway in mouse serum limit the utility of mice as experimental models of neuromyelitis optica. Mol Immunol. 2014;62(1):104-13.

28. Smajs $D$, Weinstock GM. The iron- and temperature-regulated cjrBC genes of Shigella and enteroinvasive Escherichia coli strains code for colicin Js uptake. J Bacteriol. 2001;183(13):3958-66.

29. Filip C, Fletcher G, Wulff JL, Earhart CF. Solubilization of the cytoplasmic membrane of Escherichia coli by the ionic detergent sodium-lauryl sarcosinate. J Bacteriol. 1973;115(3):717-22.

30. Kariyawasam S, Wilkie BN, Hunter DB, Gyles CL. Systemic and mucosal antibody responses to selected cell surface antigens of avian pathogenic Escherichia coli in experimentally infected chickens. Avian Dis. 2002;46(3): 668-78.

31. Lazzaroni JC, Portalier RC. Genetic and biochemical characterization of periplasmic-leaky mutants of Escherichia coli K-12. J Bacteriol. 1981;145(3): 1351-8.

32. Lazzaroni JC, Portalier RC. Isolation and preliminary characterization of periplasmic-leaky mutants of Escherichia coli K-12 FEMS microbiology letters 5:411-416; 1979

33. Quaas R, Landt O, Grunert HP, Beineke M, Hahn U. Indicator plates for rapid detection of ribonuclease T1 secreting Escherichia coli clones. Nucleic Acids Res. 1989;17(8):3318.

34. Lloyd AL, Smith SN, Eaton KA, Mobley HL. Uropathogenic Escherichia coli suppresses the host inflammatory response via pathogenicity island genes sisA and sisB. Infect Immun. 2009;77(12):5322-33.

35. Blatt AZ, Pathan S, Ferreira VP. Properdin: a tightly regulated critical inflammatory modulator. Immunol Rev. 2016:274(1):172-90.

36. O'Flynn J, Kotimaa J, Faber-Krol R, Koekkoek K, Klar-Mohamad N, Koudijs A, Schwaeble WJ, Stover C, Daha MR, van Kooten C. Properdin binds independent of complement activation in an in vivo model of anti-glomerular basement membrane disease. Kidney Int. 2018;94(6):1141-50.

37. Spitzer D, Mitchell LM, Atkinson JP, Hourcade DE. Properdin can initiate complement activation by binding specific target surfaces and providing a platform for de novo convertase assembly. J Immunol. 2007;179(4):2600-8.

38. Prasadarao NV, Blom AM, Villoutreix BO, Linsangan LC. A novel interaction of outer membrane protein a with $\mathrm{C} 4 \mathrm{~b}$ binding protein mediates serum resistance of Escherichia coli K1. J Immunol. 2002;169(11):6352-60.

39. Li W, Wen L, Li C, Chen R, Ye Z, Zhao J, Pan J. Contribution of the outer membrane protein OmpW in Escherichia coli to complement resistance from binding to factor H. Microb Pathog. 2016;98:57-62.

40. Miajlovic H, Smith SG. Bacterial self-defence: how Escherichia coli evades serum killing. FEMS Microbiol Lett. 2014;354(1):1-9.

41. Kramer VC, Nickerson KW, Hamlett NV, O'Hara C. Prevalence of extreme detergent resistance among the Enterobacteriaceae. Can J Microbiol. 1984; 30(5):711-3.

42. Rajagopal S, Sudarsan N, Nickerson KW. Sodium dodecyl sulfate hypersensitivity of clpP and clpB mutants of Escherichia coli. Appl Environ Microbiol. 2002;68(8):4117-21.

43. Pluschke G, Mayden J, Achtman M, Levine RP. Role of the capsule and the O antigen in resistance of 018:K1 Escherichia coli to complement-mediated killing. Infect Immun. 1983;42(3):907-13.

44. Weiser JN, Gotschlich EC. Outer membrane protein a (OmpA) contributes to serum resistance and pathogenicity of Escherichia coli K-1. Infect Immun. 1991:59(7):2252-8.

45. Eriksson J, Eriksson OS, Jonsson AB. Loss of meningococcal PilU delays microcolony formation and attenuates virulence in vivo. Infect Immun. 2012;80(7):2538-47.

46. Sahly H, Podschun $R$, Oelschlaeger TA, Greiwe M, Parolis H, Hasty D, Kekow J, Ullmann U, Ofek I, Sela S. Capsule impedes adhesion to and invasion of epithelial cells by Klebsiella pneumoniae. Infect Immun. 2000;68(12):6744-9.

47. Brooimans RA, Stegmann AP, van Dorp WT, van der Ark AA, van der Woude FJ, van Es LA, Daha MR. Interleukin 2 mediates stimulation of complement C3 biosynthesis in human proximal tubular epithelial cells. J Clin Invest. 1991;88(2):379-84

48. Li K, Feito MJ, Sacks SH, Sheerin NS. CD46 (membrane cofactor protein) acts as a human epithelial cell receptor for internalization of opsonized uropathogenic Escherichia coli. J Immunol. 2006;177(4):2543-51.

49. Li K, Sacks SH, Sheerin NS. The classical complement pathway plays a critical role in the opsonisation of uropathogenic Escherichia coli. Mol Immunol. 2008;45(4):954-62 
50. Seelen MA, Brooimans RA, van der Woude FJ, van Es LA, Daha MR. IFNgamma mediates stimulation of complement C4 biosynthesis in human proximal tubular epithelial cells. Kidney Int. 1993;44(1):50-7.

51. Song D, Zhou W, Sheerin SH, Sacks SH. Compartmental localization of complement component transcripts in the normal human kidney. Nephron. 1998;78(1):15-22.

52. Springall T, Sheerin NS, Abe K, Holers VM, Wan H, Sacks SH. Epithelial secretion of $\mathrm{C} 3$ promotes colonization of the upper urinary tract by Escherichia coli. Nat Med. 2001;7(7):801-6.

53. Mackay SL, Dankert JR. Bacterial killing and inhibition of inner membrane activity by C5b-9 complexes as a function of the sequential addition of $\mathrm{C} 9$ to C5b-8 sites. J Immunol. 1990;145(10):3367-71.

54. Wright SD, Levine RP. How complement kills E. coli. I. Location of the lethal lesion. J Immunol. 1981;127(3):1146-51.

55. Godlewska R, Wisniewska K, Pietras Z, Jagusztyn-Krynicka EK. Peptidoglycanassociated lipoprotein (pal) of gram-negative bacteria: function, structure, role in pathogenesis and potential application in immunoprophylaxis. FEMS Microbiol Lett. 2009;298(1):1-11.

56. Webster RE. The Tol gene products and the import of macromolecules into Escherichia coli. Mol Microbiol. 1991;5(5):1005-11.

57. Troxell B, Hassan HM. Transcriptional regulation by ferric uptake regulator (Fur) in pathogenic bacteria. Front Cell Infect Microbiol. 2013;3:59.

58. Cascales E, Buchanan SK, Duche D, Kleanthous C, Lloubes R, Postle K, Riley M, Slatin S, Cavard D. Colicin biology. Microbiol Mol Biol Rev. 2007;71(1): $158-229$.

\section{Publisher's Note}

Springer Nature remains neutral with regard to jurisdictional claims in published maps and institutional affiliations.

Ready to submit your research? Choose BMC and benefit from:

- fast, convenient online submission

- thorough peer review by experienced researchers in your field

- rapid publication on acceptance

- support for research data, including large and complex data types

- gold Open Access which fosters wider collaboration and increased citations

- maximum visibility for your research: over $100 \mathrm{M}$ website views per year

At $\mathrm{BMC}$, research is always in progress.

Learn more biomedcentral.com/submissions 